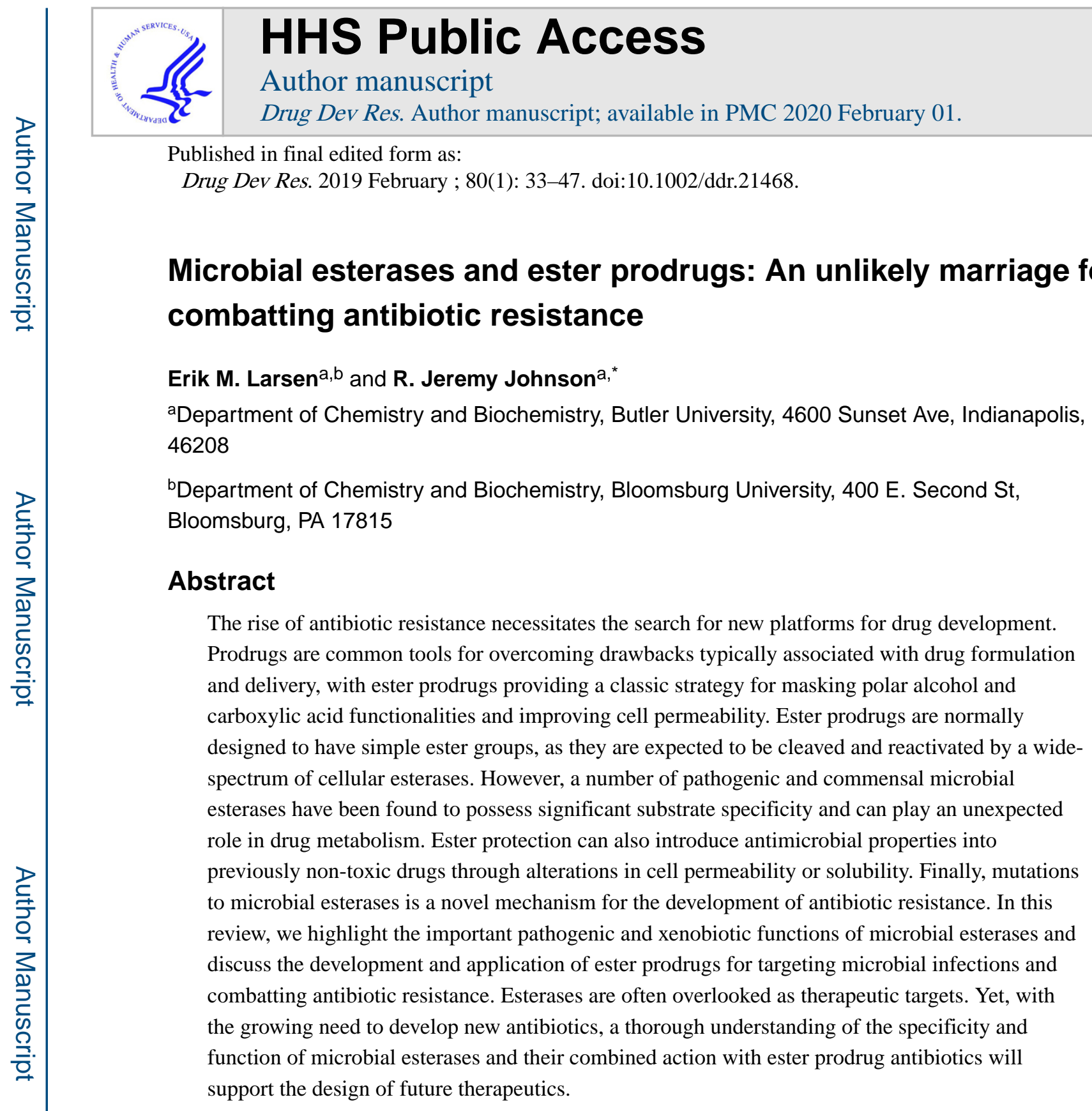

\title{
Keywords
}

Esterases; Prodrugs; Antibiotic resistance; Drug design; Drug delivery; Mycobacterium tuberculosis

\begin{abstract}
Antibiotic resistance is a growing global health issue driven by a complex web of scientific, societal, and economic factors.[Silver 2011; World_Health_Organization 2014] Predictions for the spread of antibiotic resistance suggest that multi-drug resistant infections will become increasingly common over the next 50 years and that we are currently moving into a post-antibiotic era.[Alanis 2005; World_Health_Organization 2014] Multiple large foundations and governmental entities have made antibiotic resistance a top priority of their
\end{abstract}

\footnotetext{
*Correspondence should be addressed to: R. Jeremy Johnson; rjjohns1@ butler.edu; Phone: 1-317-940-9062.
} 
funding and educational efforts (UK Longitude Prize; https://longitudeprize.org/ and US National Institutes of Health Antimicrobial Resistance Diagnostic Challenge; https:// dpcpsi.nih.gov/AMRChallenge/), but the development of new antibiotics is still slower than the spread of antibiotic resistance.[Fischbach and Walsh 2009] Combatting antibiotic resistance will require a multi-pronged approach from targeted antibiotic use, optimization of current treatments, and development of antibiotics with new modes of action.[Goff et al. 2017; Melander and Melander 2017]

Another promising strategy for combatting antibiotic resistance is to resurrect discarded antibiotics by reducing undesired side-effects and improving target affinity.[Maviglia et al. 2009; Nass et al. 2017] Synthesizing prodrug versions of an antibiotic is one confirmed method for masking activity or shifting toxicity.[Blondiaux et al. 2017; Istvan et al. 2017; Pires et al. 2015] A prodrug is an inactive version of a drug that is administered to a patient and activated either extracellularly or intracellularly by an enzymatic or chemical process to expose the active drug.[Clas et al. 2014] Prodrugs have been commonly employed by medicinal chemists to improve the pharmacodynamic properties of a lead compound and to mask polar groups to increase cell permeability.[Benedetto Tiz et al. 2018; Testa 2009] Multiple recent FDA approved drugs, including new antibiotics, are marketed as prodrugs. [Abet et al. 2017; Rautio et al. 2017] Prodrug antibiotics are a powerful strategy for combatting antibiotic resistance as they can overcome the difficulty of crossing the bacterial cell wall and can effectively target recalcitrant organisms like Mycobacterium tuberculosis. [Benedetto Tiz et al. 2018; Herrmann et al. 2017; Hoagland et al. 2016; Mori et al. 2017; Singh and Mizrahi 2017]

One classic prodrug strategy with applications for antibacterial development is to mask polar functionalities such as alcohols or carboxylic acids by turning them into esters, thus improving cell permeability.[Hamada 2017; Testa 2009] Traditionally, esters were designed to be generally activated by ubiquitous human esterases, but with an increased understanding of esterase substrate specificity, these functionalities can now be tuned to target specific human esterases or to shift the localization of prodrug activation.[Hamada 2017; Yang et al. 2011; Zou et al. 2018] Reviews of the prodrug activating function of human esterases, including their substrate specificity, activity, and potential druggability have been published. [Satoh and Hosokawa 2006; Yang et al. 2011; Zou et al. 2018] In this review, we focus on bacterial esterases, their connection to the virulence and survival of bacterial pathogens, their confirmed roles in prodrug activation, and their future applications for combatting antibiotic resistance.

\section{Bacterial esterases}

Esterases in their classic form catalyze the conversion of an ester to a carboxylic acid and an alcohol by a hydrolysis reaction, utilizing a catalytic triad of a nucleophilic serine, general base histidine, and activating acidic residue.[Carr and Ollis 2009; Holmquist 2000; Sousa et al. 2015] However, this generalization of esterase activity glosses over the diversity and complexity of this enzyme superfamily, with members able to selectively catalyze the hydrolysis of diverse chemical bonds including esters, thioesters, phosphoesters, amides, and epoxides.[Busto et al. 2010; Jochens et al. 2011; Kourist et al. 2010; Martinez-Martinez et

Drug Dev Res. Author manuscript; available in PMC 2020 February 01. 
al. 2018] Microbial esterases are also often promiscuous, with individuals possessing the overlapping ability to hydrolyze esters, thioesters, and phosphoesters.[Kovačić et al. 2013; Kuznetsova et al. 2005] The arrangement of catalytic residues also varies, from triads of SerHis-Asp and Ser-Ser-Lys to catalytic diads of Ser-Lys, Ser-His, and Ser-Asp.[Lescic Asler et al. 2017; Long and Cravatt 2011; Wilhelm et al. 2011] In this section, we will provide an overview of two large subclasses of bacterial esterases, differentiate their structures and functions, and summarize their roles in bacterial growth and virulence. We also highlight new methodology for characterizing microbial esterases and introduce microbial esterases with confirmed roles in ester prodrug activation.

\section{M. tuberculosis esterases}

Exemplifying the diversity of microbial esterases and their varied biological roles are $M$. tuberculosis (Mtb) esterases, with over 40 putative $M t b$ esterases predicted based on computational analysis.[Tallman et al. 2016b] The expansion of esterase activity in $M t b$ as compared to humans or other bacteria is likely connected to its diverse metabolic pathways, its ability to scavenge host cell lipids for energy, and its unique lifestyle, which transitions between dormant and active growth states.[Singh et al. 2010; Tallman et al. 2016b] Mtb esterases are involved in the virulence and survival of $M t b$, as nonspecific esterase inhibitors such as tetrahydrolipstatin, lalistat, and mmPOX interfere with bacterial growth and survival. [Delorme et al. 2012; Goins et al. 2018; Rens et al. 2016] Most interestingly, esterase inhibition retards growth in the dormant state, where the majority of approved TB drugs are inactive.[Delorme et al. 2012] Slight modifications of these nonspecific esterase inhibitors also provided modest selectivity for $M t b$, indicating that $M t b$ esterases may be potential novel antibacterial targets.[Goins et al. 2018; Lehmann et al. 2018; West et al. 2011]

The majority of these 40 identified $M t b$ esterases are predicted to fit within the traditional a/ $\beta$-hydrolase protein family, with a structural fold composed of eight $\beta$-strands forming a lefthanded, superhelically twisted $\beta$-sheet surrounded by a-helices (Figure 1A).[Dedieu et al. 2013; Singh et al. 2010; Tallman et al. 2016b] In this fold, the nucleophilic serine is contained with a nucleophilic elbow demarcated by a G-x-S-x-G motif and located at least 100 amino acids from the N-terminus (Figure 1A and 1B).[Carr and Ollis 2009; Holmquist 2000] Structural and functional differentiation within $\alpha / \beta$-hydrolase family members is then controlled by inserted loops and secondary structural elements, especially within the lid or cap domain that can undergo interfacial activation in the presence of lipid substrates (Figure 1C and 1D).[Kourist et al. 2010; Li et al. 2015; Yang et al. 2015] Only a limited number of three-dimensional structures for mycobacterial esterases have been determined, but each showcase this classic a/ $\beta$-hydrolase protein fold.[Crellin et al. 2010; McKary et al. 2016; Zheng et al. 2011] This is exemplified by the structures of LipW and Rv0045c, two proposed metabolic hydrolases from $M t b$ (Figure 1C and 1D). Each of these enzymes show overlapping $\alpha / \beta$-hydrolase structural folds, but differentiation in their cap/lid domains and substrate binding pockets.[McKary et al. 2016; Zheng et al. 2011] This differential substrate binding pocket gives them unique ester substrate specificity, which is directly related to the structure and properties of their binding pocket architecture.[Lukowski et al. 2014; McKary et al. 2016]

Drug Dev Res. Author manuscript; available in PMC 2020 February 01. 
One class of $M t b$ esterases with an expanding role in the virulence of $M t b$ is esterases containing PE and PPE domains.[Sultana et al. 2016] The PE and PPE domain families are a Mycobacteria specific protein family that are named based on their N-terminal prolineglutamate (PE) or proline-proline-glutamate (PPE) motifs.[Cole et al. 1998] The PE and PPE domain family is expanded in pathogenic mycobacterial species, with $167 \mathrm{PE} / \mathrm{PPE}$ domain proteins identified in the slow-growing $M t b$ but only 2 members in the fast-growing and nonpathogenic mycobacterial model organism, Mycobacterium smegmatis.[Cole et al. 1998; Sultana et al. 2016] PE and PPE domain proteins are connected to the antigenicity, immune regulation, and virulence of $M t b$. [Fishbein et al. 2015] Within the larger PE and PPE domain families, eight family members were identified computationally as containing a predicted $\alpha / \beta$-hydrolase protein fold.[Sultana et al. 2011] These eight $\alpha / \beta$-hydrolase PE and PPE domain family members were nicknamed the PE-PPE domain subfamily, as each member has a $\mathrm{C}$-terminal domain, encoding a predicted $\alpha / \beta$-hydrolase protein fold and an $\mathrm{N}$-terminal PE or PPE domain.[Sultana et al. 2011] These family members have been confirmed as esterases and modeled onto an $\alpha / \beta$-hydrolase protein fold with a classic catalytic triad.[Singh et al. 2016; Sultana et al. 2013; Vemula et al. 2018] The most wellstudied of this family - PE11 (Rv1169c or LipX) - plays a role in biofilm growth, creates an immunogenic response, and affects levels of virulence-related lipids.[Rastogi et al. 2017; Singh et al. 2016] The combined effect of PE11 on virulence lipids and biofilm growth suggests a biological role dependent on its esterase activity. Interestingly, the effect on biofilm growth varies based on expression of PE11 in Mtb or M. smegmatis.[Rastogi et al. 2017] As most PE and PPE domain family members are membrane associated or excreted, these PE-PPE domain esterases might make good partners with ester prodrugs and are being explored as novel mode of action drug targets.

Another class of $M t b$ esterases that are confirmed antibacterial targets and are extracellularly localized are esterases active against endogenous host lipids, especially essential nutrient sources for Mtb like triacylglycerol (TAG).[Deb et al. 2006; Dedieu et al. 2013; Delorme et al. 2012] TAG is a good energy source for dormant or reactivating $M t b$, making enzymes involved in collecting host TAG or in utilizing TAG stores in $M t b$ promising drug targets for dormant TB infection.[Low et al. 2009] The initial TAG esterase identified was LipY (Rv3097c).[Deb et al. 2006] LipY contains a PE domain that modulates its activity and targets LipY for secretion by the ESX-5 pathway.[Daleke et al. 2011; Garrett et al. 2015; Mishra et al. 2008] Deletion of LipY interferes with the degradation of intracellular lipid stores and restoration of growth from dormancy.[Mishra et al. 2008] LipY is also involved in the immune response to $M t b$, as LipY overexpression led to a more robust immune response and diminished the efficacy of the Mycobacterium bovis BCG vaccine to protect against TB infection.[Singh et al. 2014; Singh et al. 2011] LipY could make a good partner for prodrug esters, as it has wide substrate specificity but a well-defined structure activity relationship. [Delorme et al. 2012; Satpati et al. 2016; Saxena et al. 2013] Recently, Msh1 (mycobacterial secreted hydrolase) was identified as a second TAG hydrolyzing esterase, which is specific for host lipid hydrolysis.[Singh et al. 2017] Since it targets host lipids, catalyzes ester hydrolysis outside $M t b$, and is upregulated during hypoxic conditions, Msh1 could also represent a novel drug target and ester prodrug activating partner.[Singh et al. 2017] 
To track the full repertoire of $M t b$ esterases, multiple recent studies have identified the proteome-wide esterase activity of $M t b$ and followed the change in $M t b$ esterase activity in relation to disease conditions. [Lehmann et al. 2018; Ortega et al. 2016; Ravindran et al. 2014; Tallman et al. 2016b] Using activity-based protein profiling (ABPP) and various mechanism-based inhibitors (Figure 2A-2D), over 80 different serine hydrolases have been tagged across four recent $M t b$ ABPP studies.[Tallman et al. 2016b] With diverse targeting ligands including tetrahydrolipstatin (THL; Figure 2A and 2B) and fluorophosphonate (Figure 2C and 2D) derivatives, each of these proteomic ABPP studies have found overlapping, but distinct subpopulations of esterase activity. Importantly, they have each identified esterases that remain active under dormant growth conditions. [Lehmann et al. 2018; Ortega et al. 2016; Ravindran et al. 2014; Tallman et al. 2016b] The distinct subclasses of esterases mapped from each study may relate to small variations in ABPP ligand properties, but interestingly none of these four studies have isolated LipY despite THL and fluorophosphonates being known inhibitors.[Tallman et al. 2016b] A recent study tried to make these ABPP probes more selective for $M t b$ by modifying THL to more closely mimic mycolic acids that are unique to the $M t b$ membrane (Figure 2B). [Lehmann et al. 2018] This THL derivative selectively targeted two Mtb serine hydrolases (Pks13 and Ag85) and enhanced the potency of frontline TB therapeutics by over 100-fold when used in combination therapy.[Lehmann et al. 2018]

As a complementary approach to proteome-wide ABPP, fluorogenic ester probes have showcased the intragenus and intrastrain variation of esterase activity and pinpointed unique hydrolase activity upregulated during dormant growth conditions (Figure 2E and 2F). [Bassett et al. 2018; Tallman and Beatty 2015; Tallman et al. 2016a; Tallman et al. 2016b] Complementary turn-on fluorogenic ester scaffolds have each highlighted the broad reactivity of mycobacterial esterases with the ability to hydrolyze short chain, long chain, branched, and polar esters.[Bassett et al. 2018; Johnson et al. 2014; Lukowski et al. 2014; Tallman and Beatty 2015; Tallman et al. 2016a; Tallman et al. 2016b] Importantly for prodrug ester design, dormant mycobacterial esterase activity showed a skewed substrate distribution, with its esterases preferring longer, more hydrophobic esters (Figure 2F). [Bassett et al. 2018] These differentially activated esters represent promising starting points for introducing selectivity into ester prodrugs. Overall, the differential expression of $M t b$ esterases under various disease conditions and their key roles in nutrient scavenging and utilization make them promising novel drug targets. The diversity of ester reactivity present within $M t b$ esterases makes them well-positioned for targeted ester prodrug design to synergistically localize the active drug to the $M t b$ infection site and overcome the complex cell permeability of $M t b$.

\section{Pseudomonas aeruginosa esterases}

One of the most studied families of microbial esterases are the secreted and cell-surface attached esterases from Pseudomonas aeruginosa, an opportunistic pathogen.[Komnatnyy et al. 2014; Wagner et al. 2016] The overlapping but distinct roles of three extracellular $P$. aeruginosa esterases in bacterial growth, survival, and biofilm formation illustrate the diverse functions, structures, and properties of microbial esterases.[Funken et al. 2011; Komnatnyy et al. 2014; Rosenau et al. 2010; Wilhelm et al. 2011] Comparison of these $P$. 
aeruginosa esterases to homologues from nontoxic or commensal Pseudomonas species also illustrates the emergent virulent properties of pathogenic esterases.[Leščić Ašler et al. 2010; Nicolay et al. 2012; Wilhelm et al. 2011]

The best-studied of these $P$. aeruginosa esterases is EstA, an autotransporter-conjugated extracellular esterase with roles in biofilm formation, motility, and rhamnolipid processing. [Tielen et al. 2010; van den Berg 2010; Wilhelm et al. 2007] In this autotransporter architecture, the N-terminal domain encodes the esterase domain of EstA, which is then connected through an extended, kinked helix to the $\mathrm{C}$-terminal membrane-spanning $\beta$-barrel domain (Figure 1E). [van den Berg 2010] EstA is one of the 30 most abundant proteins on the outer membrane and within outer membrane vesicles of $P$. aeruginosa.[Couto et al. 2015] Many autotransporter proteins are then cleaved once they reach the outer membrane, but EstA remains covalently bound to its membrane-spanning autotransporter domain (Figure 1E).[Couto et al. 2015; Wilhelm et al. 2011] As an esterase, EstA is strongly selective for short ester substrates with a selective substrate profile for butyl esters.[Leščić Ašler et al. 2010] Inactivation of the catalytic serine in EstA within $P$. aeruginosa strains led to various phenotypes including loss of biofilm formation, increased solution viscosity, and decreased cell motility.[Wilhelm et al. 2007] These phenotypes are likely connected to EstA's ability to cleave rhamnolipid, an abundant biosurfactant from $P$. aeruginosa composed of mono- and di-rhamnose linked to 3-hydroxy fatty acids.[Tielen et al. 2010; Wilhelm et al. 2007] Interestingly, these virulence and biofilm related phenotypes are not conserved in EstA homologues from nonpathogenic Pseudomonas relatives, Pseudomonas stutzeri A15 and Pseudomonas putida.[Nicolay et al. 2012; Wilhelm et al. 2011] This difference in phenotype might be related to the narrower substrate specificity of EstA from $P$. aeruginosa as compared to its homologue from $P$. putida, even though they share over $>60 \%$ sequence similarity.[Leščić Ašler et al. 2010]

The hydrolase domain of EstA is also an archetype of another large structural class of bacterial esterases, the GSDL family of hydrolases, which are named for the GSDL motif surrounding the catalytic serine (Figure 1F). [van den Berg 2010; Wilhelm et al. 2011] EstA resides within the SGNH subfamily of GSDL hydrolases, distinguished by the presence of a key catalytic residue within four conserved sequence blocks.[Wilhelm et al. 2011] GSDL hydrolases differ from the $\alpha / \beta$-hydrolase domain esterases, as GSDL hydrolases do not have a nucleophilic elbow for their catalytic serine, have their nucleophilic serine located close to the $\mathrm{N}$-terminus, and adopt a three-layered $\alpha / \beta / \alpha$ structure with five $\beta$-strands and at least four a-helices.[Wilhelm et al. 2011] SGNH hydrolases like EstA are confirmed virulence factors in various pathogenic organisms, including Moraxella bovis, Vibrio harveyi, Salmonella enterica, and Yersinia enterocolitica, making this an important esterase subclass for antibiotic development.[Flores-Díaz et al. 2016] Unlike EstA from P. aeruginosa, which has no measurable phospholipase activity, many of these virulence-related GSDL esterases are phospholipases and are involved in membrane synthesis or inflammatory responses. [Flores-Díaz et al. 2016; Hiller et al. 2017; Lang and Flieger 2011]

In addition to EstA, $P$. aeruginosa contains two other secreted esterases with roles in growth, survival, and biofilm formation.[Tielen et al. 2010] Similar to EstA, LipC effects cell aggregation, biofilm formation, and rhamnolipid processing.[Rosenau et al. 2010] However, 
the mode of action for biofilm control by LipC is likely different from EstA as a LipC deletion effected the gene expression profile of PhoP, a response regulator protein controlling biofilm formation.[Rosenau et al. 2010] LipA, another $P$. aeruginosa esterase, shows no effect on biofilm formation, but surprisingly still binds the biofilm aggregate alginate with high affinity.[Rosenau et al. 2010; Tielen et al. 2013] Instead, LipA deletion shows a phenotypic effect on iron-dependent signaling and levels of the sigma factor PvdS through an unidentified gene expression mechanism.[Funken et al. 2011] The LipA homologue in the nosocomial pathogen, Acitenobacter baumannii, is required for growth on long-chain fatty acids and increases this pathogen's fitness and colonization.[Johnson et al. 2016] Together these esterases from $P$. aeruginosa illustrate the diversity of functions, properties, and structures present within bacterial esterases and showcase their potential for drug targeting and prodrug activation.

\section{Emerging microbial esterase drug targets}

The therapeutic applications of esterases has continued to expand, especially as higher throughput analysis of virulence factors and esterases are probed more widely.[Bachovchin and Cravatt 2012; Kolbe et al. 2018] Recently, the esterases from Staphylococcus aureus were analyzed by ABPP, identifying ten previously uncharacterized and evolutionarily divergent serine hydrolases nicknamed FphA-J (fluorophosphonate-binding hydrolases). [Lentz et al. 2018] Through the development of selective chemical probes, the esterase FphB with specificity for short chain esters was found to be essential for establishing infection but dispensable to growth under normal conditions. Based on the localization of FphB on the cell surface and at the division septum, FphB was proposed to serve a purpose like $M t b$ esterases and to process host-derived nutrients to facilitate $S$. aureus growth and survival. The novel function for FphB in controlling $S$. aureus infectivity within specific organs (heart and liver versus kidney) suggests important, undiscovered biological roles for various bacterial esterases, especially at the host-pathogen interface.[Lentz et al. 2018]

Another antibacterial target with a growing connection between its esterases, its virulence, and its survival is Francisella tularensis, a highly toxic, endemic gram-negative bacterium. [Llewellyn et al. 2011; Su et al. 2007; Weiss et al. 2007] Screens of virulence factors for $F$. tularensis identified multiple putative esterases with potential roles in virulence.[Chen et al. 2017; Su et al. 2007; Weiss et al. 2007] Follow-up experiments have confirmed these putative esterases as active esterases with unusual substrate specificity and proposed biological roles in xenobiotic or host ester degradation.[Chen et al. 2017; Farberg et al. 2016] These $F$. tularensis esterases are also membrane bound and excreted in outer membrane vesicles making them accessible for ester prodrug activation.[Chen et al. 2017; Filippova et al. 2013; Smith et al. 2018] Conversion of weakly active antibacterials into prodrug esters to target $F$. tularensis is already a confirmed strategy for increasing the cell penetration of polar antibacterials.[McKenney et al. 2012] These prodrugs were then activated intracellularly by unidentified endogenous $F$. tularensis esterases.

Although not a bacterial esterase, the recent description of a prodrug activating esterase from Plasmodium falciparum clearly illustrates the potential, but also challenges, of ester prodrugs for microbial diseases.[Istvan et al. 2017] The therapeutic form of the antimalarial

Drug Dev Res. Author manuscript; available in PMC 2020 February 01. 
drug pepstatin was found to be the minor contaminant pepstatin butyl ester (Figure 2G). Pepstatin butyl ester overcomes the poor bioavailability of pepstatin and then becomes activated intracellularly by PfPARE ( $P$. falciparum Prodrug Activation and Resistance Esterase), a novel prodrug activating esterase in $P$. falciparum.[Istvan et al. 2017] The matching of PfPARE substrate specificity with the antimalarial activity of ester-protected pepstatin derivatives suggests that ester protection and PfPARE could serve as a connected system for designing novel ester prodrugs for malaria. PfPARE prodrug activation was also transferrable to the intracellular activation of another malaria drug (MMV011438; Figure 2G).[Istvan et al. 2017] Conversely, resistance mutations were also developed in PfPARE that inactivated the anti-malarial activity of ester-protected pepstatin, illustrating the difficulty in generally applying this prodrug strategy.[Cowell et al. 2018; Istvan et al. 2017] This resistance has also been confirmed by combined evolution and chemogenomics, with PfPARE only showing resistance mutations against the two ester containing antimalarial drugs.[Cowell et al. 2018] Overall, PfPare and the pepstatin ester prodrugs showcase the ability to match ester prodrugs with intracellular esterases from pathogenic organisms and to use ester prodrugs to overcome the poor bioavailability of the parent compound. In the next section, we delineate the design and successful implementation of ester prodrug antibiotics and how ester prodrug design can be used to overcome bacterial resistance mechanisms.

\section{Esterase-activated prodrugs}

Matching with the diversity of microbial esterases, ester prodrugs have been designed with diverse properties, reactive groups, and targeting mechanisms. In the classic application of ester prodrugs, polar functionalities are masked to improve pharmaceutical properties or to alleviate unwanted side effects. The ubiquity of esterases within pathogenic targets also allows for a targeted approach, where the masking polar functionalities improve cell penetration and are selectively activated within the microbe. In this section, we cover recent reports of ester prodrugs designed to target pathogenic microbes that fall into these two categories. We also highlight emerging ester prodrug approaches that expand the chemistry and applications of this strategy.

\section{Classical prodrugs}

The classic approach to ester prodrugs is to design them solely for better tissue mobility. These ester prodrugs are then nonspecifically hydrolyzed by human esterases such as carboxylesterases 1 and 2 and are often activated far from the target site.[Beaumont et al. 2003] A large number of prodrugs designed to target microbes use this mechanism to improve the pharmacokinetic and pharmacodynamic properties of otherwise unsuitable therapeutics.[Beaumont et al. 2003; Kratky and Vinsova 2011; Maag 2007; Mizen and Burton 2002] Several common antibiotics have ester prodrugs in clinical use, which we will cover in this section. Additionally, we focus on three recent examples of successful implementation of this strategy and highlight key features for ester prodrug design. These examples represent modern applications of classic ester prodrug design in antibiotic development. Ester protection not only shifts a drug's polarity, but can also increase bioavailability, decrease toxicity, and disrupt unfavorable interdrug interactions. The human esterases activating each of these ester prodrugs were not assigned in these studies. However,

Drug Dev Res. Author manuscript; available in PMC 2020 February 01. 
new high-throughput proteomic methodology could make it easier to pinpoint the activating esterase.[Xu et al. 2015]

$\beta$-lactam agents are the most widely-used class of antibiotics, representing a significant population of commercially-available antibiotics in use.[Elander 2003] While the $\beta$-lactam ring itself is responsible for the inhibition of the transpepsidase enzymes involved in bacterial cell wall biosynthesis, the core structure of most $\beta$-lactam antibiotics includes a carboxylate (Figure 3D). This functionality, present at $\mathrm{C} 3$ in penicillins and $\mathrm{C} 4$ in cephalosporins (Figure 3D), interacts with a lysine in the transpeptidase active site and is crucial for substrate binding.[Fenollar-Ferrer et al. 2002] However, the ionic nature of the carboxylate limits oral bioavailability, which has guided efforts to improve lipophilicity and gastrointestional absorption since the early days of penicillin research.[Richardson et al. 1945] Ampicillin is a broad-spectrum $\beta$-lactam antibiotic that possesses low toxicity but incomplete absorption when administered orally, with only 30-40\% being excreted in humans.[Ferres 1983; Sjövall et al. 1978] A number of ester prodrugs of ampicillin have been developed over the years (pivampicillin, talampicillin, bacampicillin, lenampicillin) to improve oral bioavailability (Figure 3D). [Bodin et al. 1975; Clayton et al. 1976; Sakamoto et al. 1984; Sjövall et al. 1978] These compounds provide significant improvements in maximum serum concentrations, nearly quadrupling that of ampicillin. [Mizen and Burton 2002]

Colistin (Figure 3A) is a cyclic lipopeptide member of the polymyxin family used as a lastline drug for the treatment of multi-drug resistant (MDR) gram-negative bacterial infections. [Lim et al. 2010] The neuro- and nephrotoxicity of colistin prevents use for systematic administration.[Spapen et al. 2011] One avenue to limit its toxicity is to formulate it into a prodrug such as colistin methanesulfonate (CMS, Figure 3A), though this compound suffers from variable release rates.[Bergen et al. 2006] Conjugating colistin to a polyethylene glycol methyl ether (mPEG) polymer results in a compound that is stable at room temperature but labile at body temperature $\left(37^{\circ} \mathrm{C}\right)$. [Zhu et al. 2017] MIC testing found that the mono-aaPEG compound (col-aaPEG) had in vitro performance rivalling that of colistin and superior to that of CMS, and in vivo testing found no evidence of nephrotoxicity in a mouse model. While this prodrug does not target bacterial esterases, it highlights that ester linkages can be tuned to modify otherwise unsuitable antibiotics into potential clinical prodrugs.

Ciprofloxacin (Figure 3E) is a broad-spectrum second generation fluoroquinone antibiotic that is effective against most gram-negative and many gram-positive bacteria.[Chin and Neu 1984] The low aqueous solubility and intestinal permeability of ciprofloxacin has led the investigation of $\mathrm{C} 3$ ethylene glycol prodrugs, believed to disrupt the crystal lattice of the flat, rigid structure (Figure 3E). [Assali et al. 2016] These prodrug derivatives incorporated mono-, di-, and tri-ethylene glycol, moieties that are known to be safe in humans, in three synthetic steps. Higher solubility was observed in mono-, di-, and tri-ethylene glycol derivatives, with ciprofloxacin-TEG being nearly 400 times as soluble. All three compounds were also largely stable at different $\mathrm{pH}$ values. Introduction of an esterase enzyme resulted in quick hydrolysis and restoration of antimicrobial activity, demonstrating that ethylene glycol ester prodrugs can provide a safe and efficient means of improving pharmaceutical properties while maintaining efficacy.

Drug Dev Res. Author manuscript; available in PMC 2020 February 01. 
Fosmidomycin and its acetyl derivative FR900098 (Figure 3F) are natural products hypothesized to inhibit a key enzyme (Dxr) in the non-mevalonate pathway of isoprenoid synthesis found to be essential in several organisms, including malaria, Mtb, and Escherichia coli.[Jomaa et al. 1999; Wiesner et al. 2000] Both compounds have seen interest in clinical development, with FR900098 showing particular effectiveness against malaria,[Jomaa et al. 1999] but both suffer from low oral bioavailability due to high ionization of the phosphono moiety and a subsequent lack of lipophilicity. Converting the phosphono functionality to a phosphonate acetyloxyethyl ester functionality on FR900098 (Figure 3F) was found to double its effectiveness at reducing parasitaemia in a mouse model when compared with the parent compound.[Ortmann et al. 2003] Testing of plasma levels confirmed that the compound exhibited increased oral bioavailability.

\section{Targeted ester prodrugs and conjugates}

Aside from alterations to the basic physicochemical properties, ester prodrugs can be designed to explicitly target microbial esterases. In these cases, the ester functionality of the prodrug is still designed to improve the lipophilicity of the drug and to increase cell penetration, but as compared to general prodrug activations, these targeted ester prodrugs penetrate through bacterial cell walls to deliver the compound intracellularly. There, it is hydrolyzed to the active form by internal bacterial esterases. Such prodrugs frequently demonstrate significant improvements to biological activity when compared to the unmodified compound.

Pyrazinamide (PZA) is a front-line medication against $M t b$, and one of the most efficient agents in killing slow-growing bacilli inside the granuloma (Figure 3C). PZA interferes with membrane energy metabolism and function, but its exact mechanism of action remains unknown.[Shi et al. 2018; Zhang and Mitchison 2003; Zhang et al. 2013; Zhang et al. 2003] The current hypothesis is that PZA's actions are dependent on its conversion to pyrazinoic acid (POA) through hydrolysis by pyrazinamidase within $M t b$, since some resistant strains do not express this enzyme.[Konno et al. 1967; Scorpio and Zhang 1996] As PZA is already a prodrug of POA, there have been a number of investigations into developing POA esters as therapeutic alternatives.[Bergmann et al. 1996; Cynamon et al. 1995; Cynamon et al. 1992] Early efforts found that several POA esters had improved activity against $M t b$ as compared to PZA, but the most promising compounds were later found to possess poor stability in plasma.[Bergmann et al. 1996] Increasing the chain length of the ester functionality improves stability in plasma and rat liver homogenate, with chains in excess of 12 carbons showing a 10-fold improvement in MIC against a PZA-susceptible strain of Mtb. [Simões et al. 2009] A recent follow-up study found that these esters were active against mycobacteria with resistance to PZA, including a strain (M. avium) hypothesized to have natural resistance due to a POA efflux mechanism. [Pires et al. 2015] In this instance, the antimycobacterial activity was thought to be a result of the released long-chain alcohol, which are also known to have lethal effects following in vivo oxidation to the alkanol. [Kanetsuna 1985] Against $M t b$, resistance was hypothesized to be overcome by a combination of both POA and the long-chain alcohol.[Pires et al. 2015] The unexpected synergistic action of the ester-protecting group and POA suggested that careful consideration 
of the ester targeting moiety may provide dual benefits beyond solely increasing cell permeability.

Recently, these POA esters were also investigated for specificity against non-replicating $M t b$.[Segretti et al. 2016] Tested POA esters included ester moieties with variable alkyl chain lengths and heteroatom substitutions, as well as a pair of "duplicated" prodrugs designed to achieve higher molar ratios of POA inside Mtb after hydrolysis (Figure 3C). These new compounds further demonstrated that more lipophilic esters achieve better MICs, but also showed that growth medium composition affected activity.[Fernandes et al. 2014; Segretti et al. 2016] Albumin-containing mediums resulted in observed activity up to 10 times lower, which suggests that albumin bound to the POA esters. Testing these prodrugs in a low-oxygen recovery assay (LORA)[Cho et al. 2007] designed to detect activities of antimicrobial agents against non-replicating $M t b$ showed that $\mathrm{pH}$ changes had an effect on POA ester activity that was not observed with PZA, suggesting a different mechanism of action in low-oxygen conditions. The duplicated prodrugs also showed notable activity, with compound $\mathbf{1}$ having an MIC half that of its mono counterpart 2, though the low $\log \mathrm{P}$ values resulting from the extra pyrazinoate moiety may have prevented it from reaching its full potential.[Segretti et al. 2016] Overall these derivatives showed interesting activity with very low cytotoxicity, with the duplicated prodrugs warranting additional attention as a method to increase POA concentration intracellularly.

To investigate the prodrug activating esterases from $M t b$, a recent screen was developed that uses ester prodrugs of a TB-specific antibiotic to globally characterize mycobacterial esterase activity and substrate specificity (Figure 3B).[Larsen et al. 2017] A small initial library of dual acylation ethambutol derivatives was produced by selective o-acylation, which gave these prodrugs in high yield and purity.[Kristensen et al. 2009] Ethambutol is a front-line antibiotic for TB with a simple structure that targets mycobacterial cell wall synthesis.[Telenti et al. 1997] Importantly for this ester prodrug design, the two primary alcohols on ethambutol are essential to its antimycobacterial properties[Häusler et al. 2001] and ester protection of these alcohols inactivates ethambutol until selective removal by an esterase. Screening this ester-protected library against the slow-growing non-infectious model mycobacterium M. smegmatis found that biological activity was significantly attenuated in the ester-protected form. Incubating these prodrugs with a general esterase pig liver esterase (PLE) - successfully reactivated the derivatives.[Larsen et al. 2017] Future combination of this ester-protected ethambutol strategy with high activity esters from other $M t b$ ester prodrugs, like POA esters, may help increase the selectivity of these esterprotected ethambutol derivatives.

In addition to their development for antimalarial purposes, fosmidomycin and FR900098 have been explored as antibacterial and antitubercular agents. Protecting the phosphonate ester of FR900098 using a pivaloyloxymethyl (POM) functionality yields a compound with an MIC of $50-100 \mu \mathrm{g} / \mathrm{mL}$ against $M t b$ where the parent compound is essentially inactive (Figure 3F).[Uh et al. 2011] These prodrugs also demonstrated inhibitory activity against gram-negative bacteria possessing a mutation known to confer resistance to fosmidomycin and FR900098 treatment.[McKenney et al. 2012] A recent analogue program centering on $\mathrm{N}$-acyl and O-linked analogues of FR900098 as a means to further improve antitubercular 
activity also noted that POM-esters of the new compounds displayed the best $\mathrm{IC}_{50}$ values compared to phosphonate and phosphonate ethers.[San Jose et al. 2016] Analogues developed by other groups have also employed this moiety.[Phillips et al. 2015]

Another subcategory of ester prodrugs designed to be selectively activated by intracellular esterases are prodrug conjugates, where the active compound is bound to a secondary molecule. In one example, ciprofloxacin was bound to a single-walled carbon nanotube through an ethylene glycol linker to create a nanoantibiotic (Figure 3E).[Assali et al. 2017] Here, the nanotubes would enter the bacteria through damage to the bacterial cell wall, whereupon the linker could be cleaved by carboxylesterase enzymes within the bacteria. The nanoantibiotic was found to possess high hydrolytic stability and dispersability and possessed low cytotoxicity against human cell lines. The nanotubes impaired bacterial efflux pumps and caused bacterial aggregation,[Arias and Yang 2009; Yang et al. 2010] which significantly increases exposure to ciprofloxacin. Biological activity against E. coli, $S$. aureus, and $P$. aeruginosa was found to be 8-16 times better with the nanoantibiotic vs. ciprofloxacin alone.[Assali et al. 2017] In a similar vein, a ciprofloxacin anhydride linkage to a ChemMatrix resin yields an antibacterial coating, which is cleaved by extracellular bacterial esterases to prevent the formation of biofilms (Figure 3E).[Komnatnyy et al. 2014] Testing of these antibiotic beads against wild-type $P$. aeruginosa resulted in the complete destruction of the strain within 4 hours, whereas beads modified to be amide-bonded had no antibiotic effect, providing another application for the $P$. aeruginosa esterases (Figure $1 \mathrm{E}$ and 1F).

One strategy to limit the spread of antibiotic resistance is through the use of narrowspectrum antibiotics, which can be designed by attaching a targeting moiety to an otherwise broad-spectrum antibiotic.[Lewis 2013] Siderophores, low-molecular-weight iron chelators used by some gram-negative bacteria, have been used for the targeted delivery of $\beta$-lactam antibiotics.[Zheng and Nolan 2014] A recent report details the discovery of a conjugate of ciprofloxacin and the native bacterial siderophore enterobactin (3, Figure 4A), which is an inactive prodrug that is guided into the cytoplasm of $E$. coli expressing enterobactin uptake mechanisms.[Neumann et al. 2018] The siderophore can be subsequently hydrolyzed to the monocatecholate product 4 by a specific cytoplasmic esterase, IroD, expressed only by $E$. coli that harbor the pathogen-associated iro $A$ gene cluster.[Lin et al. 2005] Overall, the conjugate 3 exerts antibacterial activity similar to that of ciprofloxacin against two strains of uropathogenic $E$. coli while having no activity against non-pathogenic strains lacking the necessary gene cluster.[Neumann et al. 2018] Additional work established the necessity of the siderophore for uptake and delivery of the antibiotic, highlighting the potential of targeting pathogen-associated esterases to narrow the activity of otherwise broad-spectrum antibiotics.

\section{Novel ester prodrug strategies}

When faced with the challenge of designing a prodrug that targets esterases, the classical strategy is to simply esterify a hydroxy or carboxylic acid functionality on the compound of interest. Such strategies are effective, synthetically simple and highly economical. However, there have also been reports of alternative approaches in cases where a simple ester proved

Drug Dev Res. Author manuscript; available in PMC 2020 February 01. 
to be too unstable, or where cleavage of the ester would lead to the release of a therapeutic other than the base hydrolysis products. Here, we cover three examples of novel ester prodrugs that employ unusual strategies.

Ester prodrugs are typically made by masking polar carboxylic acids with a nonpolar ester bond. As such, there are fewer instances of ester prodrugs that release hydroxy and phenolic moieties. A recent report[Perez et al. 2013] explored the esterase activation of hydroxy and phenolic functionalities using a core scaffold for metalloenzyme inhibitors. [Agrawal et al. 2008] In addition to direct acetylation, benzyl ether and doubly acetylated catechol-based linkers were also attached to the scaffold to assess the relative kinetics and stability of different ester-responsive triggers (Figure 4B). These linkers eliminate following deacetylation to release the inhibitor, generating side products considered to be innocuous (Figure 4C). Aqueous stability tests found that compounds $\mathbf{6}$ and $\mathbf{7}$ were significantly more stable than $\mathbf{5}$ and liberated the parent inhibitor approximately 4 and 8 times faster, respectively, upon treatment with PLE, demonstrating the utility of the benzyl ether linkage. [Perez et al. 2013] Treatment of these compounds with PLE was required to restore inhibition against metalloenzymes, showing that the platform could be useful for esteraseresponsive prodrug design.

Endochin-like quinolones (ELQ) are known to target the cytochrome bc1 complex of the malaria parasite $P$. falciparum.[Nilsen et al. 2013; Nilsen et al. 2014] These compounds, such as ELQ-300 (Figure 4D), have low water solubility and high crystallinity, which limits their oral absorption, so a prodrug approach is needed to improve their physiochemical properties.[Nilsen et al. 2013] The acetyl ester was found to be unstable, so a carbonate ester prodrug (ELQ-337, Figure 4D) was instead investigated as a means of diminishing crystallinity and enhancing oral absorption. Testing showed that this prodrug had activity equivalent to ELQ-300 following activation by non-specific esterases within parasiteinfected red blood cells, and a single dose was completely curative in mice harboring a patent infection.[Miley et al. 2015] In a recent follow-up publication, the carbonate ester was replaced with an alkoxycarbonate ester, a promoiety found in some FDA-approved prodrugs. [Bodin et al. 1975] This new analogue, ELQ-331, was synthesized in a single step from ELQ-300, and showed an even lower degree of crystallinity and high performance in both in vitro and in vivo models (Figure 4D). [Frueh et al. 2017] In particular, ELQ-331 showed evidence of being cleaved by parasitic esterases in addition to host esterases, suggesting that the alkoxycarbonate moiety shows potential for further improvements to target specificity.

Carbon monoxide has seen interest as a therapeutic agent for a number of different areas, including antibacterial development.[Davidge et al. 2009] However, using CO in a clinical setting has a number of issues, a major one being its delivery to the site of interest in a controllable fashion.[Ji et al. 2016a] A recent report detailed the development of a set of metal-free $\mathrm{CO}$ prodrugs that release $\mathrm{CO}$ upon esterase activation, easing difficulties in handling and controlling the exact quantity of CO released.[Ji et al. 2017] The design for controlled $\mathrm{CO}$ release centers on conformational constraints, with an ester bond holding an alkyne dienophile away from a dienone. Upon cleavage of the ester bond by an esterase, the freed dienophile undergoes an entropically-favored intramolecular Diels-Alder cycloaddition to release CO (Figure 4E). [Ji et al. 2016b; Pan et al. 2017] Proof-of-concept compounds 
readily release $\mathrm{CO}$ in the presence of PLE and give only the expected cyclization products in their respective reactions, suggesting that the enzyme catalyzed hydrolysis is the rate limiting step. Additionally, testing against Raw 264.7 cells found that these prodrugs could deliver a sufficient quantity of $\mathrm{CO}$ in response to intracellular esterases to recapitulate COassociated anti-inflammatory effects.[Ji et al. 2017] This scaffold provides an esterase-based strategy for delivering a novel theraputic with tunable release rates.

\section{Conclusions}

Combatting antibiotic resistance is a global health issue that will require a multi-pronged strategy. Microbial esterases and ester prodrugs are one strategy for developing new therapeutics, better targeting current therapeutics, and repurposing discarded therapeutics. Moving beyond merely shifting the cell permeability of polar lead compounds, ester protection is emerging as a versatile medicinal chemistry tool for controlled release of antibacterials, for conjugated cell targeting, and for increasing disease selectivity. Improving the design and targeting of these ester prodrugs will require a complex, proteomic understanding of microbial esterase activity and the ability to target individual microbial esterases with overlapping enzymatic activity. The development of new visualization tools and high-throughput ligands for esterases has facilitated the identification of novel diseaserelevant esterases. These tools now need to be applied to track the differential expression of esterases under disease-relevant growth conditions, like dormancy and host-pathogen interactions. Wider implementation of ester prodrugs and microbial esterases to combat antibiotic resistance will require moving beyond the traditional view of ester prodrugs as solely a medicinal chemistry strategy for shifting drug solubility. Instead, microbial esterases and ester prodrugs represent a wealth of unexplored disease-related drug targets and creative strategies for targeting novel antibiotics. When combined, microbial esterases and ester prodrugs create a promising strategy for combatting antibiotic resistance.

\section{Acknowledgments:}

E.M.L. and R.J.J. were supported by a grant from the National Institutes of Health (NIH 1 R15 GM110641-01A1).

\section{References:}

Abet V, Filace F, Recio J, Alvarez-Builla J, Burgos C. 2017 Prodrug approach: An overview of recent cases. Eur J Med Chem 127:810-827. [PubMed: 27823878]

Agrawal A, Romero-Perez D, Jacobsen JA, Villarreal FJ, Cohen SM. 2008 Zinc-binding groups modulate selective inhibition of MMPs. ChemMedChem 3(5):812-820. [PubMed: 18181119]

Alanis AJ. 2005 Resistance to antibiotics: are we in the post-antibiotic era? Arch Med Res 36(6):697705. [PubMed: 16216651]

Arias LR, Yang L. 2009 Inactivation of bacterial pathogens by carbon nanotubes in suspensions. Langmuir 25(5):3003-3012. [PubMed: 19437709]

Assali M, Joulani M, Awwad R, Assad M, Almasri M, Kittana N, Zaid AN. 2016 Facile synthesis of ciprofloxacin prodrug analogues to improve its water solubility and antibacterial activity. Chemistry select 1(6):1132-1135.

Assali M, Zaid AN, Abdallah F, Almasri M, Khayyat R. 2017 Single-walled carbon nanotubesciprofloxacin nanoantibiotic: strategy to improve ciprofloxacin antibacterial activity. Int J Nanomed 12:6647.

Drug Dev Res. Author manuscript; available in PMC 2020 February 01. 
Bachovchin DA, Cravatt BF. 2012 The pharmacological landscape and therapeutic potential of serine hydrolases. Nat Rev Drug Discov 11(1):52-68. [PubMed: 22212679]

Bassett B, Waibel B, White A, Hansen H, Stephens D, Koelper A, Larsen EM, Kim C, Glanzer A, Lavis LD and others 2018 Measuring the global substrate specificity of mycobacterial serine hydrolases using a library of fluorogenic ester substrates. ACS Infect Dis

Beaumont K, Webster R, Gardner I, Dack K. 2003 Design of ester prodrugs to enhance oral absorption of poorly permeable compounds: challenges to the discovery scientist. Curr Drug Metab 4(6):461485. [PubMed: 14683475]

Benedetto Tiz D, Kikelj D, Zidar N. 2018 Overcoming problems of poor drug penetration into bacteria: challenges and strategies for medicinal chemists. Expert Opin Drug Dis 13(6):497-507.

Bergen PJ, Li J, Rayner CR, Nation RL. 2006 Colistin methanesulfonate is an inactive prodrug of colistin against Pseudomonas aeruginosa. Antimicrob Agents Ch 50(6):1953-1958.

Bergmann KE, Cynamon MH, Welch JT. 1996 Quantitative Structure-activity relationships for the in vitro antimycobacterial activity of pyrazinoic acid esters. J Med Chem 39(17):3394-3400. [PubMed: 8765523]

Blondiaux N, Moune M, Desroses M, Frita R, Flipo M, Mathys V, Soetaert K, Kiass M, Delorme V, Djaout K and others 2017 Reversion of antibiotic resistance in Mycobacterium tuberculosis by spiroisoxazoline SMARt-420. Science 355(6330):1206-1211. [PubMed: 28302858]

Bodin N-O, Ekström B, Forsgren U, Jalar L-P, Magni L, Ramsay C-H, Sjöberg B. 1975 Bacampicillin: a new orally well-absorbed derivative of ampicillin. Antimicrob Agents Ch 8(5):518-525.

Busto E, Gotor-Fernandez V, Gotor V. 2010 Hydrolases: catalytically promiscuous enzymes for nonconventional reactions in organic synthesis. Chem Soc Rev 39(11):4504-23. [PubMed: 20877864]

Carr PD, Ollis DL. 2009 Alpha/beta hydrolase fold: an update. Protein Pept Lett 16(10):1137-48. [PubMed: 19508187]

Chen F, Cui G, Wang S, Nair MKM, He L, Qi X, Han X, Zhang H, Zhang J-R, Su J. 2017 Outer membrane vesicle-associated lipase FtlA enhances cellular invasion and virulence in Francisella tularensis LVS. Emerg Microbes Infect 6(7):e66. [PubMed: 28745311]

Chin N-X, Neu HC. 1984 Ciprofloxacin, a quinolone carboxylic acid compound active against aerobic and anaerobic bacteria. Antimicrob Agents Ch 25(3):319-326.

Cho SH, Warit S, Wan B, Hwang CH, Pauli GF, Franzblau SG. 2007 Low-oxygen-recovery assay for high-throughput screening of compounds against nonreplicating Mycobacterium tuberculosis. Antimicrob Agents Ch 51(4):1380-1385.

Clas SD, Sanchez RI, Nofsinger R. 2014 Chemistry-enabled drug delivery (prodrugs): recent progress and challenges. Drug Discov Today 19(1):79-87. [PubMed: 23993918]

Clayton JP, Cole M, Elson SW, Ferres H, Hanson JC, Mizen LW, Sutherland R. 1976 Preparation, hydrolysis, and oral absorption of lactonyl esters of penicillins. J Med Chem 19(12):1385-1391. [PubMed: 826629]

Cole ST, Brosch R, Parkhill J, Garnier T, Churcher C, Harris D, Gordon SV, Eiglmeier K, Gas S, Barry CE, 3rd and others 1998 Deciphering the biology of Mycobacterium tuberculosis from the complete genome sequence. Nature 393(6685):537-44. [PubMed: 9634230]

Couto N, Schooling SR, Dutcher JR, Barber J. 2015 Proteome profiles of outer membrane vesicles and extracellular matrix of Pseudomonas aeruginosa biofilms. J Proteome Res 14(10):4207-4222. [PubMed: 26303878]

Cowell AN, Istvan ES, Lukens AK, Gomez-Lorenzo MG, Vanaerschot M, Sakata-Kato T, Flannery EL, Magistrado P, Owen E, Abraham M. 2018 Mapping the malaria parasite druggable genome by using in vitro evolution and chemogenomics. Science 359(6372):191-199. [PubMed: 29326268]

Crellin PK, Vivian JP, Scoble J, Chow FM, West NP, Brammananth R, Proellocks NI, Shahine A, Le Nours J, Wilce MC and others 2010 Tetrahydrolipstatin inhibition, functional analyses, and threedimensional structure of a lipase essential for mycobacterial viability. J Biol Chem 285(39): 30050-60. [PubMed: 20656688]

Cynamon MH, Gimi R, Gyenes F, Sharpe CA, Bergmann KE, Han HJ, Gregor LB, Rapolu R, Luciano G, Welch JT. 1995 Pyrazinoic acid esters with broad spectrum in vitro antimycobacterial activity. J Med Chem 38(20):3902-3907. [PubMed: 7562923] 
Cynamon MH, Klemens SP, Chou TS, Gimi RH, Welch JT. 1992 Antimycobacterial activity of a series of pyrazinoic acid esters. J Med Chem 35(7):1212-1215. [PubMed: 1560435]

Daleke MH, Cascioferro A, de Punder K, Ummels R, Abdallah AM, van der Wel N, Peters PJ, Luirink J, Manganelli R, Bitter W. 2011 Conserved Pro-Glu (PE) and Pro-Pro-Glu (PPE) protein domains target LipY lipases of pathogenic mycobacteria to the cell surface via the ESX-5 pathway. J Biol Chem 286(21):19024-34. [PubMed: 21471225]

Davidge KS, Sanguinetti G, Yee CH, Cox AG, McLeod CW, Monk CE, Mann BE, Motterlini R, Poole RK. 2009 Carbon monoxide-releasing antibacterial molecules target respiration and global transcriptional regulators. J Biol Chem 284(7):4516-4524. [PubMed: 19091747]

Deb C, Daniel J, Sirakova TD, Abomoelak B, Dubey VS, Kolattukudy PE. 2006 A novel lipase belonging to the hormone-sensitive lipase family induced under starvation to utilize stored triacylglycerol in Mycobacterium tuberculosis. J Biol Chem 281(7):3866-75. [PubMed: 16354661]

Dedieu L, Serveau-Avesque C, Kremer L, Canaan S. 2013 Mycobacterial lipolytic enzymes: a gold mine for tuberculosis research. Biochimie 95(1):66-73. [PubMed: 22819994]

Delorme V, Diomande SV, Dedieu L, Cavalier JF, Carriere F, Kremer L, Leclaire J, Fotiadu F, Canaan S. 2012 MmPPOX inhibits Mycobacterium tuberculosis lipolytic enzymes belonging to the hormone-sensitive lipase family and alters mycobacterial growth. PLoS One 7(9):e46493. [PubMed: 23029536]

Elander R 2003 Industrial production of $\beta$-lactam antibiotics. Appl Microbiol Biot 61(5-6):385-392.

Farberg AM, Hart WK, Johnson RJ. 2016 The unusual substrate specificity of a virulence associated serine hydrolase from the highly toxic bacterium, Francisella tularensis. Biochem Biophys Rep 7:415-422. [PubMed: 28955933]

Fenollar-Ferrer C, Frau J, Vilanova B, Donoso J, Muñoz F. 2002 Molecular modelling studies on Henry-Michaelis complexes of a class-C $\beta$-lactamase and $\beta$-lactam compounds. J Mol Struct 578(1-3):19-28.

Fernandes J, Pavan FR, Leite C, Felli V. 2014 Synthesis and evaluation of a pyrazinoic acid prodrug in Mycobacterium tuberculosis. Saudi Pharm J 22(4):376-380. [PubMed: 25161383]

Ferres H 1983 Prodrugs of $\beta$-lactam antibiotics. Drugs Today 19:499-538.

Filippova EV, Weston LA, Kuhn ML, Geissler B, Gehring AM, Armoush N, Adkins CT, Minasov G, Dubrovska I, Shuvalova L and others 2013 Large scale structural rearrangement of a serine hydrolase from Francisella tularensis facilitates catalysis. J Biol Chem 288(15):10522-35. [PubMed: 23430251]

Fischbach MA, Walsh CT. 2009 Antibiotics for emerging pathogens. Science 325(5944):1089-93. [PubMed: 19713519]

Fishbein S, van Wyk N, Warren RM, Sampson SL. 2015 Phylogeny to function: PE/PPE protein evolution and impact on Mycobacterium tuberculosis pathogenicity. Mol Microbiol 96(5):901-16. [PubMed: 25727695]

Flores-Díaz M, Monturiol-Gross L, Naylor C, Alape-Girón A, Flieger A. 2016 Bacterial sphingomyelinases and phospholipases as virulence factors. Microbiol Mol Biol R 80(3):597-628.

Frueh L, Li Y, Mather MW, Li Q, Pou S, Nilsen A, Winter RW, Forquer IP, Pershing AM, Xie LH. 2017 Alkoxycarbonate ester prodrugs of preclinical drug candidate ELQ-300 for prophylaxis and treatment of malaria. ACS Infect Dis 3(10):728-735. [PubMed: 28927276]

Funken H, Knapp A, Vasil ML, Wilhelm S, Jaeger K-E, Rosenau F. 2011 The lipase LipA (PA2862) but not LipC (PA4813) from Pseudomonas aeruginosa influences regulation of pyoverdine production and expression of the sigma factor PvdS. J Bacteriol 193(20):5858-5860. [PubMed: 21840975]

Garrett CK, Broadwell LJ, Hayne CK, Neher SB. 2015 Modulation of the activity of Mycobacterium tuberculosis LipY by its PE domain. PLoS One 10(8):e0135447. [PubMed: 26270534]

Goff DA, Kullar R, Goldstein EJC, Gilchrist M, Nathwani D, Cheng AC, Cairns KA, Escandon-Vargas K, Villegas MV, Brink A and others 2017 A global call from five countries to collaborate in antibiotic stewardship: united we succeed, divided we might fail. Lancet Infect Dis 17(2):e56-e63. [PubMed: 27866945]

Drug Dev Res. Author manuscript; available in PMC 2020 February 01. 
Goins CM, Sudasinghe TD, Liu X, Wang Y, O’Doherty GA, Ronning DR. 2018 Characterization of tetrahydrolipstatin and stereoderivatives on the inhibition of essential Mycobacterium tuberculosis lipid esterases. Biochemistry 57(16):2383-2393. [PubMed: 29601187]

Hamada Y 2017 Recent progress in prodrug design strategies based on generally applicable modifications. Bioorg Med Chem Lett 27(8):1627-1632. [PubMed: 28285913]

Häusler H, Kawakami RP, Mlaker E, Severn WB, Stütz AE. 2001 Ethambutol analogues as potential antimycobacterial agents. Bioorg Med Chem Lett 11(13):1679-1681. [PubMed: 11425536]

Herrmann J, Rybniker J, Muller R. 2017 Novel and revisited approaches in antituberculosis drug discovery. Curr Opin Biotech 48:94-101. [PubMed: 28427007]

Hiller M, Lang C, Michel W, Flieger A. 2017 Secreted phospholipases of the lung pathogen Legionella pneumophila. Int J Med Microbiol

Hoagland DT, Liu J, Lee RB, Lee RE. 2016 New agents for the treatment of drug-resistant Mycobacterium tuberculosis. Adv Drug Deliv Rev 102:55-72. [PubMed: 27151308]

Holmquist M 2000 Alpha/Beta-hydrolase fold enzymes: structures, functions and mechanisms. Curr Protein Pept Sci 1(2):209-35. [PubMed: 12369917]

Istvan ES, Mallari JP, Corey VC, Dharia NV, Marshall GR, Winzeler EA, Goldberg DE. 2017 Esterase mutation is a mechanism of resistance to antimalarial compounds. Nature Comm 8:14240.

Ji X, Damera K, Zheng Y, Yu B, Otterbein LE, Wang B. 2016a Toward carbon monoxide-based therapeutics: Critical drug delivery and developability issues. J Pharm Sci 105(2):406-416. [PubMed: 26869408]

Ji X, Ji K, Chittavong V, Yu B, Pan Z, Wang B. 2017 An esterase-activated click and release approach to metal-free CO-prodrugs. Chem Comm 53(59):8296-8299. [PubMed: 28685779]

Ji X, Zhou C, Ji K, Aghoghovbia RE, Pan Z, Chittavong V, Ke B, Wang B. 2016b Click and release: a chemical strategy toward developing gasotransmitter prodrugs by using an intramolecular DielsAlder reaction. Angew Chem Int Edit 55(51):15846-15851.

Jochens H, Hesseler M, Stiba K, Padhi SK, Kazlauskas RJ, Bornscheuer UT. 2011 Protein engineering of alpha/beta-hydrolase fold enzymes. Chembiochem 12(10):1508-17. [PubMed: 21506229]

Johnson RJ, Hoops GC, Savas CJ, Kartje Z, Lavis LD. 2014 A sensitive and robust enzyme kinetic experiment using microplates and fluorogenic ester substrates. J Chem Educ 92(2):385-388.

Johnson TL, Waack U, Smith S, Mobley H, Sandkvist M. 2016 Acinetobacter baumannii is dependent on the type II secretion system and its substrate LipA for lipid utilization and in vivo fitness. J Bacteriol 198(4):711-719.

Jomaa H, Wiesner J, Sanderbrand S, Altincicek B, Weidemeyer C, Hintz M, Türbachova I, Eberl M, Zeidler J, Lichtenthaler HK. 1999 Inhibitors of the nonmevalonate pathway of isoprenoid biosynthesis as antimalarial drugs. Science 285(5433):1573-1576. [PubMed: 10477522]

Kanetsuna F 1985 Bactericidal effect of fatty acids on mycobacteria, with particular reference to the suggested mechanism of intracellular killing. Microbiol Immunol 29(2):127-141. [PubMed: 4010540]

Kolbe K, Veleti SK, Johnson EE, Cho YW, Oh S, Barry CE, 3rd. 2018 Role of chemical biology in tuberculosis drug discovery and diagnosis. ACS Infect Dis

Komnatnyy VV, Chiang WC, Tolker-Nielsen T, Givskov M, Nielsen TE. 2014 Bacteria-triggered release of antimicrobial agents. Angew Chem Int Ed 53(2):439-41.

Konno K, Feldmann FM, McDermott W. 1967 Pyrazinamide susceptibility and amidase activity of tubercle bacilli. Am Rev Respir Dis 95(3):461-469. [PubMed: 4225184]

Kourist R, Jochens H, Bartsch S, Kuipers R, Padhi SK, Gall M, Bottcher D, Joosten HJ, Bornscheuer UT. 2010 The alpha/beta-hydrolase fold 3DM database (ABHDB) as a tool for protein engineering. Chembiochem 11(12):1635-43. [PubMed: 20593436]

Kovačić F, Granzin J, Wilhelm S, Kojić-Prodić B, Batra-Safferling R, Jaeger K-E. 2013 Structural and functional characterisation of TesA-a novel lysophospholipase A from Pseudomonas aeruginosa. PloS One 8(7):e69125. [PubMed: 23874889]

Kratky M, Vinsova J. 2011 Salicylanilide ester prodrugs as potential antimicrobial agents-A review. Curr Pharm Design 17(32):3494-3505.

Drug Dev Res. Author manuscript; available in PMC 2020 February 01. 
Kristensen TE, Hansen FK, Hansen T. 2009 The selective O-acylation of hydroxyproline as a convenient method for the large-scale preparation of novel proline polymers and amphiphiles. Eur J Org Chem 2009(3):387-395.

Kuznetsova E, Proudfoot M, Sanders SA, Reinking J, Savchenko A, Arrowsmith CH, Edwards AM, Yakunin AF. 2005 Enzyme genomics: Application of general enzymatic screens to discover new enzymes. FEMS Microbiol Rev 29(2):263-79. [PubMed: 15808744]

Lang C, Flieger A. 2011 Characterisation of Legionella pneumophila phospholipases and their impact on host cells. Eur J Cell Biol 90(11):903-912. [PubMed: 21342713]

Larsen EM, Stephens DC, Clarke NH, Johnson RJ. 2017 Ester-prodrugs of ethambutol control its antibacterial activity and provide rapid screening for mycobacterial hydrolase activity. Bioorg Med Chem Lett 27(19):4544-4547. [PubMed: 28882482]

Lehmann J, Cheng TY, Aggarwal A, Park AS, Zeiler E, Raju RM, Akopian T, Kandror O, Sacchettini JC, Moody DB. 2018 An antibacterial $\beta$-Lactone kills Mycobacterium tuberculosis by disrupting mycolic acid biosynthesis. Angew Chem Int Ed 57(1):348-353.

Lentz CS, Sheldon JR, Crawford LA, Cooper R, Garland M, Amieva MR, Weerapana E, Skaar EP, Bogyo M. 2018 Identification of a $S$. aureus virulence factor by activity-based protein profiling (ABPP). Nature Chem Biol 14:609-617. [PubMed: 29769740]

Leščić Ašler I, Ivić N, Kovačić F, Schell S, Knorr J, Krauss U, Wilhelm S, Kojić-Prodić B, Jaeger KE. 2010 Probing enzyme promiscuity of SGNH hydrolases. Chembiochem 11(15):2158-2167. [PubMed: 20931591]

Leščić Ašler I, Stefanic Z, Marsavelski A, Vianello R, Kojić-Prodić B. 2017 Catalytic dyad in the SGNH hydrolase superfamily: In-depth insight into structural parameters tuning the catalytic process of extracellular lipase from Streptomyces rimosus. ACS Chem Biol 12(7):1928-1936. [PubMed: 28558229]

Lewis K 2013 Platforms for antibiotic discovery. Nature Rev Drug Disc 12(5):371.

Li P-Y, Chen X-L, Ji P, Li C-Y, Wang P, Zhang Y, Xie B-B, Qin Q-L, Su H-N, Zhou B-C. 2015 Interdomain hydrophobic interactions modulate the thermostability of microbial esterases from the hormone-sensitive lipase family. J Biol Chem 290(17):11188-11198. [PubMed: 25771540]

Lim LM, Ly N, Anderson D, Yang JC, Macander L, Jarkowski A, III, Forrest A, Bulitta JB, Tsuji BT. 2010 Resurgence of colistin: a review of resistance, toxicity, pharmacodynamics, and dosing. Pharmacotherapy 30(12):1279-1291. [PubMed: 21114395]

Lin H, Fischbach MA, Liu DR, Walsh CT. 2005 In vitro characterization of salmochelin and enterobactin trilactone hydrolases IroD, IroE, and Fes. J Am Chem Soc 127(31):11075-11084. [PubMed: 16076215]

Llewellyn AC, Jones CL, Napier BA, Bina JE, Weiss DS. 2011 Macrophage replication screen identifies a novel Francisella hydroperoxide resistance protein involved in virulence. PLoS One 6(9):e24201. [PubMed: 21915295]

Long JZ, Cravatt BF. 2011 The metabolic serine hydrolases and their functions in mammalian physiology and disease. Chem Rev 111(10):6022-63. [PubMed: 21696217]

Low KL, Rao PS, Shui G, Bendt AK, Pethe K, Dick T, Wenk MR. 2009 Triacylglycerol utilization is required for regrowth of in vitro hypoxic nonreplicating Mycobacterium bovis bacillus CalmetteGuerin. J Bacteriol 191(16):5037-43. [PubMed: 19525349]

Lukowski JK, Savas CP, Gehring AM, McKary MG, Adkins CT, Lavis LD, Hoops GC, Johnson RJ. 2014 Distinct substrate selectivity of a metabolic hydrolase from Mycobacterium tuberculosis. Biochemistry 53(47):7386-95. [PubMed: 25354081]

Maag H 2007 Prodrugs of carboxylic acids. Prodrugs. p 703-729.

Martinez-Martinez M, Coscolin C, Santiago G, Chow J, Stogios PJ, Bargiela R, Gertler C, NavarroFernandez J, Bollinger A, Thies S and others 2018 Determinants and prediction of esterase substrate promiscuity patterns. ACS Chem Biol 13(1):225-234. [PubMed: 29182315]

Maviglia R, Nestorini R, Pennisi M. 2009 Role of old antibiotics in multidrug resistant bacterial infections. Curr Drug Targets 10(9):895-905. [PubMed: 19799544]

McKary MG, Abendroth J, Edwards TE, Johnson RJ. 2016 Structural basis for the strict substrate selectivity of the mycobacterial hydrolase LipW. Biochemistry 55(51):7099-7111. [PubMed: 27936614]

Drug Dev Res. Author manuscript; available in PMC 2020 February 01. 
McKenney ES, Sargent M, Khan H, Uh E, Jackson ER, San Jose G, Couch RD, Dowd CS, van Hoek ML. 2012 Lipophilic prodrugs of FR900098 are antimicrobial against Francisella novicida in vivo and in vitro and show GlpT independent efficacy. PLoS One 7(10):e38167. [PubMed: 23077474]

Melander RJ, Melander C. 2017 The challenge of overcoming antibiotic resistance: An adjuvant approach? ACS Infect Dis 3(8):559-563. [PubMed: 28548487]

Miley GP, Pou S, Winter R, Nilsen A, Li Y, Kelly JX, Stickles AM, Mather MW, Forquer IP, Pershing AM. 2015 ELQ-300 prodrugs for enhanced delivery and single dose cure of malaria. Antimicrob Agents Ch. 01183-15.

Mishra KC, De Chastellier C, Narayana Y, Bifani P, Brown AK, Besra GS, Katoch VM, Joshi B, Balaji KN, Kremer L. 2008 Functional role of the PE domain and immunogenicity of the Mycobacterium tuberculosis triacylglycerol hydrolase LipY. Infect Immun 76(1):127-140. [PubMed: 17938218]

Mizen L, Burton G. 2002 The use of esters as prodrugs for oral delivery of $\beta$-lactam antibiotics. Integration of Pharmaceutical Discovery and Development: Springer p 345-365.

Mori G, Chiarelli LR, Riccardi G, Pasca MR. 2017 New prodrugs against tuberculosis. Drug Discov Today 22(3):519-525. [PubMed: 27649942]

Nass NM, Farooque S, Hind C, Wand ME, Randall CP, Sutton JM, Seipke RF, Rayner CM, O'Neill AJ. 2017 Revisiting unexploited antibiotics in search of new antibacterial drug candidates: the case of $\gamma$-actinorhodin. Sci Rep 7(1):17419. [PubMed: 29234001]

Neumann W, Sassone-Corsi M, Raffatellu M, Nolan EM. 2018 Esterase-catalyzed siderophore hydrolysis activates an enterobactin-ciprofloxacin conjugate and confers targeted antibacterial activity. J Am Chem Soc 140(15):5193-5201. [PubMed: 29578687]

Nicolay T, Devleeschouwer K, Vanderleyden J, Spaepen S. 2012 Characterization of Esterase A, a Pseudomonas stutzeri A15 autotransporter. Appl Environ Microb 78(8):2533-2542.

Nilsen A, LaCrue AN, White KL, Forquer IP, Cross RM, Marfurt J, Mather MW, Delves MJ, Shackleford DM, Saenz FE. 2013 Quinolone-3-diarylethers: a new class of antimalarial drug. Sci Transl Med 5(177):177ra37-177ra37.

Nilsen A, Miley GP, Forquer IP, Mather MW, Katneni K, Li Y, Pou S, Pershing AM, Stickles AM, Ryan E. 2014 Discovery, synthesis, and optimization of antimalarial 4 (1 H)-quinolone-3diarylethers. J Med Chem 57(9):3818-3834. [PubMed: 24720377]

Ortega C, Anderson LN, Frando A, Sadler NC, Brown RW, Smith RD, Wright AT, Grundner C. 2016 Systematic survey of serine hydrolase activity in Mycobacterium tuberculosis defines changes associated with persistence. Cell Chem Biol 23(2):290-8. [PubMed: 26853625]

Ortmann R, Wiesner J, Reichenberg A, Henschker D, Beck E, Jomaa H, Schlitzer M. 2003 Acyloxyalkyl ester prodrugs of FR900098 with improved in vivo anti-malarial activity. Bioorg Med Chem Lett 13(13):2163-2166. [PubMed: 12798327]

Pan Z, Chittavong V, Li W, Zhang J, Ji K, Zhu M, Ji X, Wang B. 2017 Organic CO prodrugs: Structure-CO-release rate relationship studies. Chem-Eur J 23(41):9838-9845. [PubMed: 28544290]

Perez C, Daniel KB, Cohen SM. 2013 Evaluating prodrug strategies for esterase-triggered release of alcohols. ChemMedChem 8(10):1662-1667. [PubMed: 23929690]

Phillips AMF, Nogueira F, Murtinheira F, Barros MT. 2015 Synthesis and antimalarial evaluation of prodrugs of novel fosmidomycin analogues. Biorg Med Chem Lett 25(10):2112-2116.

Pires D, Valente E, Simoes MF, Carmo N, Testa B, Constantino L, Anes E. 2015 Esters of pyrazinoic acid are active against pyrazinamide-resistant strains of Mycobacterium tuberculosis and other naturally resistant mycobacteria in vitro and ex vivo within macrophages. Antimicrob Agents $\mathrm{Ch}$ 59(12):7693-9.

Rastogi S, Singh AK, Pant G, Mitra K, Sashidhara KV, Krishnan MY. 2017 Down-regulation of PE11, a cell wall associated esterase, enhances the biofilm growth of Mycobacterium tuberculosis and reduces cell wall virulence lipid levels. Microbiology 163(1):52-61. [PubMed: 28198348]

Rautio J, Karkkainen J, Sloan KB. 2017 Prodrugs - Recent approvals and a glimpse of the pipeline. Eur J Pharm Sci 109:146-161. [PubMed: 28782609]

Ravindran MS, Rao SP, Cheng X, Shukla A, Cazenave-Gassiot A, Yao SQ, Wenk MR. 2014 Targeting lipid esterases in mycobacteria grown under different physiological conditions using activity- 
based profiling with tetrahydrolipstatin (THL). Mol Cell Proteomics 13(2):435-48. [PubMed: 24345785]

Rens C, Laval F, Daffé M, Denis O, Frita R, Baulard A, Wattiez R, Lefèvre P, Fontaine V. 2016 Effects of lipid-lowering drugs on vancomycin susceptibility of mycobacteria. Antimicrob Agents $\mathrm{Ch}$ 60(10):6193-6199.

Richardson AP, Walker HA, Loeb P, Miller I. 1945 The experimental basis for the quantitative chemotherapy of $B$. novyi in mice with a comparison of action of penicillin and dichlorphenarsine hydrochloride. J Pharmacol Exp Ther 85(1):23-35. [PubMed: 21004437]

Rosenau F, Isenhardt S, Gdynia A, Tielker D, Schmidt E, Tielen P, Schobert M, Jahn D, Wilhelm S, Jaeger K-E. 2010 Lipase LipC affects motility, biofilm formation and rhamnolipid production in Pseudomonas aeruginosa. FEMS Microbiol Lett 309(1):25-34. [PubMed: 20546309]

Sakamoto F, Ikeda S, Tsukamoto G. 1984 Studies on prodrugs. II. Preparation and characterization of (5-substituted 2-oxo-1, 3-dioxolen-4-yl) methyl esters of ampicillin. Chem Pharm Bulletin 32(6): 2241-2248.

San Jose G, Jackson ER, Haymond A, Johny C, Edwards RL, Wang X, Brothers RC, Edelstein EK, Odom AR, Boshoff HI. 2016 Structure-activity relationships of the MEPicides: N-Acyl and OLinked analogs of FR900098 as inhibitors of Dxr from Mycobacterium tuberculosis and Yersinia pestis. ACS Infect Dis 2(12):923-935. [PubMed: 27676224]

Satoh T, Hosokawa M. 2006 Structure, function and regulation of carboxylesterases. Chem Biol Interact 162(3):195-211. [PubMed: 16919614]

Satpati S, Behera P, Dixit A. 2016 Identification of LipY inhibitors as antitubercular agents using stepwise virtual screening. Int J Pharm Chem Biol Sci 6(4).

Saxena AK, Roy KK, Singh S, Vishnoi SP, Kumar A, Kashyap VK, Kremer L, Srivastava R, Srivastava BS. 2013 Identification and characterisation of small-molecule inhibitors of Rv3097c-encoded lipase (LipY) of Mycobacterium tuberculosis that selectively inhibit growth of bacilli in hypoxia. Int J Antimicrob Ag 42(1):27-35.

Scorpio A, Zhang Y. 1996 Mutations in pncA, a gene encoding pyrazinamidase/nicotinamidase, cause resistance to the antituberculous drug pyrazinamide in tubercle bacillus. Nature Med 2(6):662. [PubMed: 8640557]

Segretti ND, Simões CK, Corrêa MF, Felli VMA, Miyata M, Cho SH, Franzblau SG, dos Santos Fernandes JP. 2016 Antimycobacterial activity of pyrazinoate prodrugs in replicating and nonreplicating Mycobacterium tuberculosis. Tuberculosis 99:11-16. [PubMed: 27449999]

Shi W, Chen J, Zhang S, Zhang W, Zhang Y. 2018 Identification of novel mutations in LprG (rv1411c), rv0521, rv3630, rv0010c, ppsC, cyp128 associated with pyrazinoic acid/pyrazinamide resistance in Mycobacterium tuberculosis. Antimicrob Agens Ch. 00430-18.

Silver LL. 2011 Challenges of antibacterial discovery. Clin Microbiol Rev 24(1):71-109. [PubMed: 21233508]

Simões MF, Valente E, Gómez MJR, Anes E, Constantino L. 2009 Lipophilic pyrazinoic acid amide and ester prodrugs: stability, activation and activity against $M$. tuberculosis. Eur J Pharm Sci 37(3-4):257-263. [PubMed: 19491013]

Singh G, Jadeja D, Kaur J. 2010 Lipid hydrolizing enzymes in virulence: Mycobacterium tuberculosis as a model system. Crit Rev Microbiol 36(3):259-69. [PubMed: 20500016]

Singh KH, Jha B, Dwivedy A, Choudhary E, Arpitha G, Ashraf A, Arora D, Agarwal N, Biswal BK. 2017 Characterization of a secretory hydrolase from Mycobacterium tuberculosis sheds critical insight into host lipid utilization by M. tuberculosis. J Biol Chem 292(27):11326-11335. [PubMed: 28515317]

Singh P, Rao RN, Reddy JRC, Prasad R, Kotturu SK, Ghosh S, Mukhopadhyay S. 2016 PE11, a $\mathrm{PE} / \mathrm{PPE}$ family protein of Mycobacterium tuberculosis is involved in cell wall remodeling and virulence. Sci Rep 6:21624. [PubMed: 26902658]

Singh V, Mizrahi V. 2017 Identification and validation of novel drug targets in Mycobacterium tuberculosis. Drug Discov Today 22(3):503-509. [PubMed: 27649943]

Singh VK, Srivastava M, Dasgupta A, Singh MP, Srivastava R, Srivastava BS. 2014 Increased virulence of Mycobacterium tuberculosis H37Rv overexpressing LipY in a murine model. Tuberculosis 94(3):252-261. [PubMed: 24631199]

Drug Dev Res. Author manuscript; available in PMC 2020 February 01. 
Singh VK, Srivastava V, Singh V, Rastogi N, Roy R, Shaw AK, Dwivedi AK, Srivastava R, Srivastava BS. 2011 Overexpression of Rv3097c in Mycobacterium bovis BCG abolished the efficacy of BCG vaccine to protect against Mycobacterium tuberculosis infection in mice. Vaccine 29(29-30):4754-4760. [PubMed: 21565242]

Sjövall J, Magni L, Bergan T. 1978 Pharmacokinetics of bacampicillin compared with those of ampicillin, pivampicillin, and amoxycillin. Antimicrob Agents Ch 13(1):90-96.

Smith MA, Phillips WK, Rabin PL, Johnson RJ. 2018 A dynamic loop provides dual control over the catalytic and membrane binding activity of a bacterial serine hydrolase. BBA-Proteins Proteom 1866 (9):925-932.

Sousa SrF Ramos MJ, Lim C Fernandes PA. 2015 Relationship between enzyme/substrate properties and enzyme efficiency in hydrolases. ACS Catal 5(10):5877-5887.

Spapen H, Jacobs R, Van Gorp V, Troubleyn J, Honoré PM. 2011 Renal and neurological side effects of colistin in critically ill patients. Ann Intensive Care 1(1):14. [PubMed: 21906345]

Su J, Yang J, Zhao D, Kawula TH, Banas JA, Zhang JR. 2007 Genome-wide identification of Francisella tularensis virulence determinants. Infect Immun 75(6):3089-101. [PubMed: 17420240]

Sultana R, Tanneeru K, Guruprasad L. 2011 The PE-PPE domain in mycobacterium reveals a serine a/ $\beta$ hydrolase fold and function: an in-silico analysis. PloS One 6(2):e16745. [PubMed: 21347309]

Sultana R, Tanneeru K, Kumar AB, Guruprasad L. 2016 Prediction of certain well-characterized domains of known functions within the PE and PPE proteins of Mycobacteria. PloS One 11(2):e0146786. [PubMed: 26891364]

Sultana R, Vemula MH, Banerjee S, Guruprasad L. 2013 The PE16 (Rv1430) of Mycobacterium tuberculosis is an esterase belonging to serine hydrolase superfamily of proteins. PloS One 8(2):e55320. [PubMed: 23383323]

Tallman KR, Beatty KE. 2015 Far-red fluorogenic probes for esterase and lipase detection. ChemBioChem 16(1):70-75. [PubMed: 25469918]

Tallman KR, Levine SR, Beatty KE. 2016a Profiling esterases in Mycobacterium tuberculosis using far-red fluorogenic substrates. ACS Chem Biol 11(7):1810-5. [PubMed: 27177211]

Tallman KR, Levine SR, Beatty KE. 2016b Small-Molecule probes reveal esterases with persistent activity in dormant and reactivating Mycobacterium tuberculosis. ACS Infect Dis 2(12):936-944. [PubMed: 27690385]

Telenti A, Philipp WJ, Sreevatsan S, Bernasconi C, Stockbauer KE, Wieles B, Musser JM, Jacobs WR, Jr. 1997 The emb operon, a gene cluster of Mycobacterium tuberculosis involved in resistance to ethambutol. Nature Med 3(5):567. [PubMed: 9142129]

Testa B 2009 Prodrugs: bridging pharmacodynamic/pharmacokinetic gaps. Curr Opin Chem Biol 13(3):338-44. [PubMed: 19473869]

Tielen P, Kuhn H, Rosenau F, Jaeger K-E, Flemming H-C, Wingender J. 2013 Interaction between extracellular lipase LipA and the polysaccharide alginate of Pseudomonas aeruginosa. BMC Microbiol 13(1):159. [PubMed: 23848942]

Tielen P, Rosenau F, Wilhelm S, Jaeger K-E, Flemming H-C, Wingender J. 2010 Extracellular enzymes affect biofilm formation of mucoid Pseudomonas aeruginosa. Microbiology 156(7): 2239-2252. [PubMed: 20360178]

Uh E, Jackson ER, San Jose G, Maddox M, Lee RE, Lee RE, Boshoff HI, Dowd CS. 2011 Antibacterial and antitubercular activity of fosmidomycin, FR900098, and their lipophilic analogs. Bioorg Med Chem Lett 21(23):6973-6976. [PubMed: 22024034]

van den Berg B 2010 Crystal structure of a full-length autotransporter. J Mol Biol 396(3):627-633. [PubMed: 20060837]

Vemula M, Balakrishnan K, Banerjee S, Guruprasad L. 2018 Mycobacterium tuberculosis PE1 and PE2 proteins carrying conserved $\alpha / \beta$-serine hydrolase domain are esterases hydrolyzing short to medium chain p-nitrophenyl esters. Prog Biophys Mol Biol. 10.1016/j.pbiomolbio.2018.04.012

Wagner S, Sommer R, Hinsberger S, Lu C, Hartmann RW, Empting M, Titz A. 2016 Novel strategies for the treatment of Pseudomonas aeruginosa infections. J Med Chem 59(13):5929-5969. [PubMed: 26804741] 
Weiss DS, Brotcke A, Henry T, Margolis JJ, Chan K, Monack DM. 2007 In vivo negative selection screen identifies genes required for Francisella virulence. Proc Natl Acad Sci U S A 104(14): 6037-42. [PubMed: 17389372]

West NP, Cergol KM, Xue M, Randall EJ, Britton WJ, Payne RJ. 2011 Inhibitors of an essential mycobacterial cell wall lipase (Rv3802c) as tuberculosis drug leads. Chem. Commun. (Camb) 47(18):5166-8. [PubMed: 21384024]

Wiesner J, Hintz M, Altincicek B, Sanderbrand S, Weidemeyer C, Beck E, Jomaa H. 2000 Plasmodium falciparum: detection of the deoxyxylulose 5-phosphate reductoisomerase activity. Exp Parasit 96(3):182-186. [PubMed: 11162369]

Wilhelm S, Gdynia A, Tielen P, Rosenau F, Jaeger K-E. 2007 The autotransporter esterase EstA of Pseudomonas aeruginosa is required for rhamnolipid production, cell motility, and biofilm formation. J Bacteriol 189(18):6695-6703. [PubMed: 17631636]

Wilhelm S, Rosenau F, Kolmar H, Jaeger KE. 2011 Autotransporters with GDSL passenger domains: molecular physiology and biotechnological applications. Chembiochem 12(10):1476-1485. [PubMed: 21598370]

World_Health_Organization. 2014 Antimicrobial resistance - Global Report on Surveillance.

Xu H, Majmudar JD, Davda D, Ghanakota P, Kim KH, Carlson HA, Showalter HD, Martin BR, Amidon GL. 2015 Substrate-competitive activity-based profiling of ester prodrug activating enzymes. Mol Pharm 12(9):3399-3407. [PubMed: 26262434]

Yang C, Mamouni J, Tang Y, Yang L. 2010 Antimicrobial activity of single-walled carbon nanotubes: length effect. Langmuir 26(20):16013-16019. [PubMed: 20849142]

Yang S, Qin Z, Duan X, Yan Q, Jiang Z. 2015 Structural insights into the substrate specificity of two esterases from the thermophilic Rhizomucor miehei. J Lip Res 56(8):1616-1624.

Yang Y-h, Aloysius H, Inoyama D, Chen Y, Hu L-q. 2011 Enzyme-mediated hydrolytic activation of prodrugs. Acta Pharmaceut Sin B 1(3):143-159.

Zhang Y, Mitchison D. 2003 The curious characteristics of pyrazinamide: a review. Int J Tuberc Lung D 7(1):6-21.

Zhang Y, Shi W, Zhang W, Mitchison D. 2013 Mechanisms of pyrazinamide action and resistance. Microbiol Spectr 2(4):1. [PubMed: 25530919]

Zhang Y, Wade MM, Scorpio A, Zhang H, Sun Z. 2003 Mode of action of pyrazinamide: disruption of Mycobacterium tuberculosis membrane transport and energetics by pyrazinoic acid. J Antimicrob Chemoth 52(5):790-795.

Zheng T, Nolan EM. 2014 Enterobactin-mediated delivery of $\beta$-lactam antibiotics enhances antibacterial activity against pathogenic Escherichia coli. J Am Chem Soc 136(27):9677-9691. [PubMed: 24927110]

Zheng X, Guo J, Xu L, Li H, Zhang D, Zhang K, Sun F, Wen T, Liu S, Pang H. 2011 Crystal structure of a novel esterase Rv0045c from Mycobacterium tuberculosis. PLoS One 6(5):e20506. [PubMed: 21637775]

Zhu C, Schneider EK, Wang J, Kempe K, Wilson P, Velkov T, Li J, Davis TP, Whittaker MR, Haddleton DM. 2017 A traceless reversible polymeric colistin prodrug to combat multidrugresistant (MDR) gram-negative bacteria. J Control Release 259:83-91. [PubMed: 28174100]

Zou LW, Jin Q, Wang DD, Qian QK, Hao DC, Ge GB, Yang L. 2018 Carboxylesterase inhibitors: An update. Curr Med Chem 25(14):1627-1649. [PubMed: 29210644]

Drug Dev Res. Author manuscript; available in PMC 2020 February 01. 


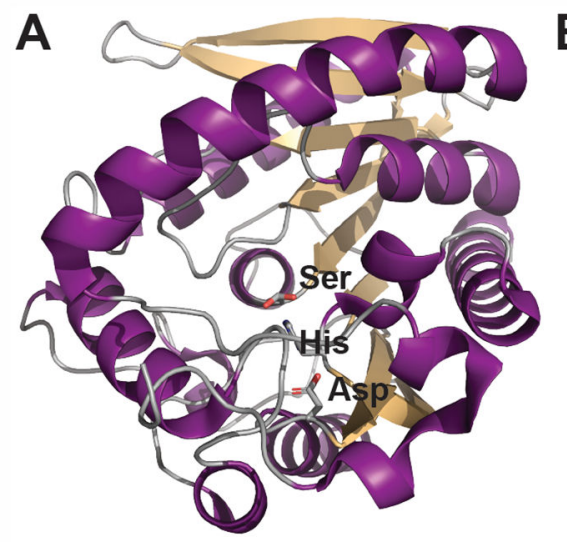

B
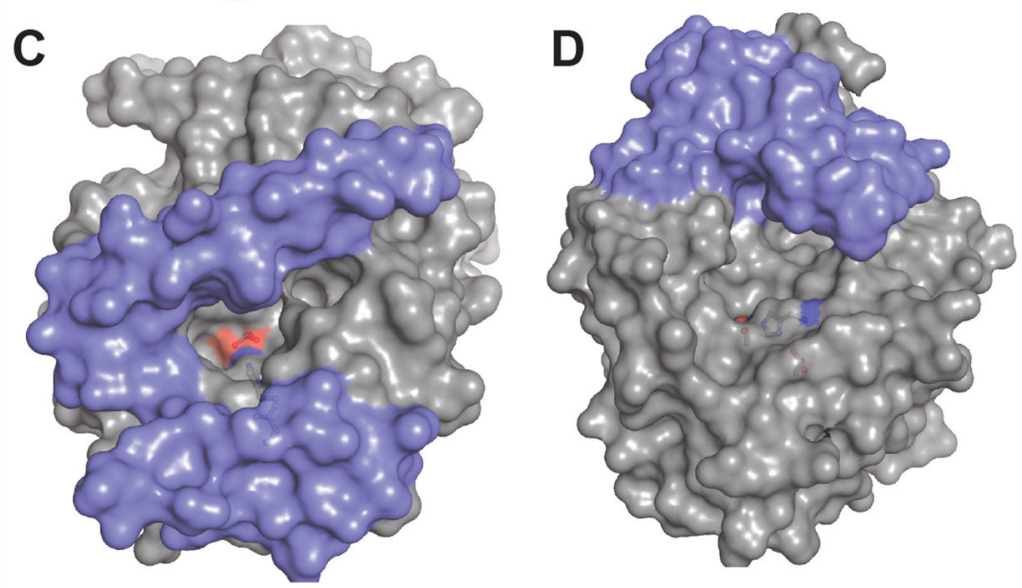

$\mathrm{E}$
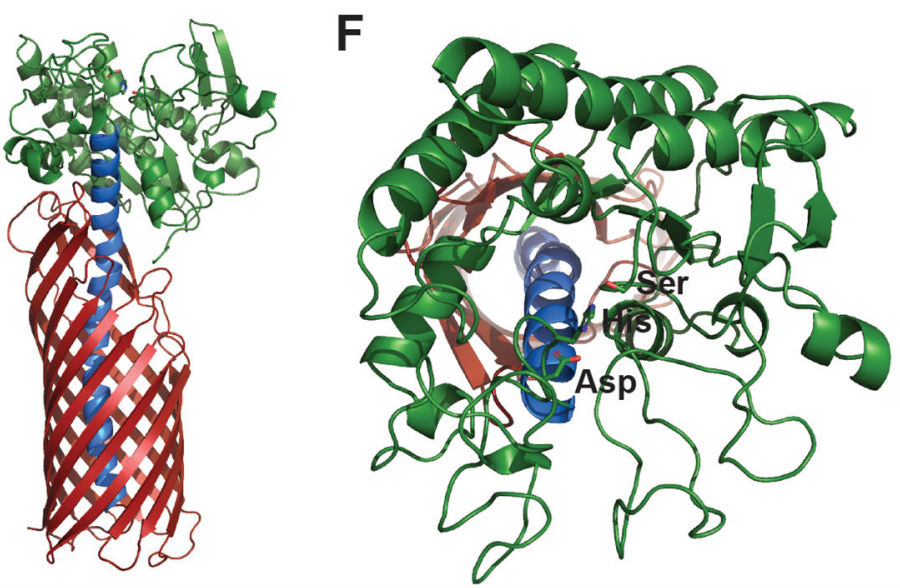

Figure 1:

Bacterial esterase structure and function. A) Classic $\alpha / \beta$-hydrolase structural fold present in many bacterial esterases.[Carr and Ollis 2009; Holmquist 2000] This a/ $\beta$-hydrolase structural fold is composed of a left-handed, twisted $\beta$-sheet surrounded by $a$-helices and encircling a centrally located catalytic triad.[Carr and Ollis 2009] The bacterial esterase, LipW from M. tuberculosis (PDB ID: 3QH4) is shown as an example with its $\beta$-sheets in tan, its a-helices in purple, and its catalytic triad in sticks and labeled. The catalytic serine of LipW was observed in dual rotameric conformations.[McKary et al. 2016] These 
conformations have been observed in other $a / \beta$-hydrolase structures and have been related to the catalytic mechanism of esterases, including facilitating product release and inhibiting the reverse reaction.[McKary et al. 2016] B) Close up of the catalytic triad from LipW with the hydrogen bonding network that facilitates the nucleophilicity of the catalytic serine shown with black dotted lines.[McKary et al. 2016] Colored identically to A. C and D) Substrate differentiating cap/lid structure of $\alpha / \beta$-hydrolases. Surface structures of LipW (C) [McKary et al. 2016] and Rv0045c (D; PDB ID: 3P2M) [Zheng et al. 2011]; two Mtb esterases with varying substrate specificity and binding pocket structures.[Lukowski et al. 2014; McKary et al. 2016] Cap/lid regions are shown in blue with the remaining residues in gray. The catalytic triad is shown in sticks and is colored by atom type. E) Full-length autotransporter EstA from $P$. aeruginosa (PDB ID: 3KVN).[van den Berg 2010] The Nterminal domain (green) encodes the esterase functionality with the membrane spanning $\beta$ barrel (red) domain connected to the esterase domain through an extended kinked helix (blue). F) The GSDL protein fold. The GSDL protein fold exemplified by the esterase domain of Est $A$ contains a three-layered $a / \beta / a$ structure with five $\beta$-strands and at least four a-helices.[van den Berg 2010; Wilhelm et al. 2011] EstA is colored identically to E. The catalytic triad is shown in sticks and is colored by atom type.

Drug Dev Res. Author manuscript; available in PMC 2020 February 01. 

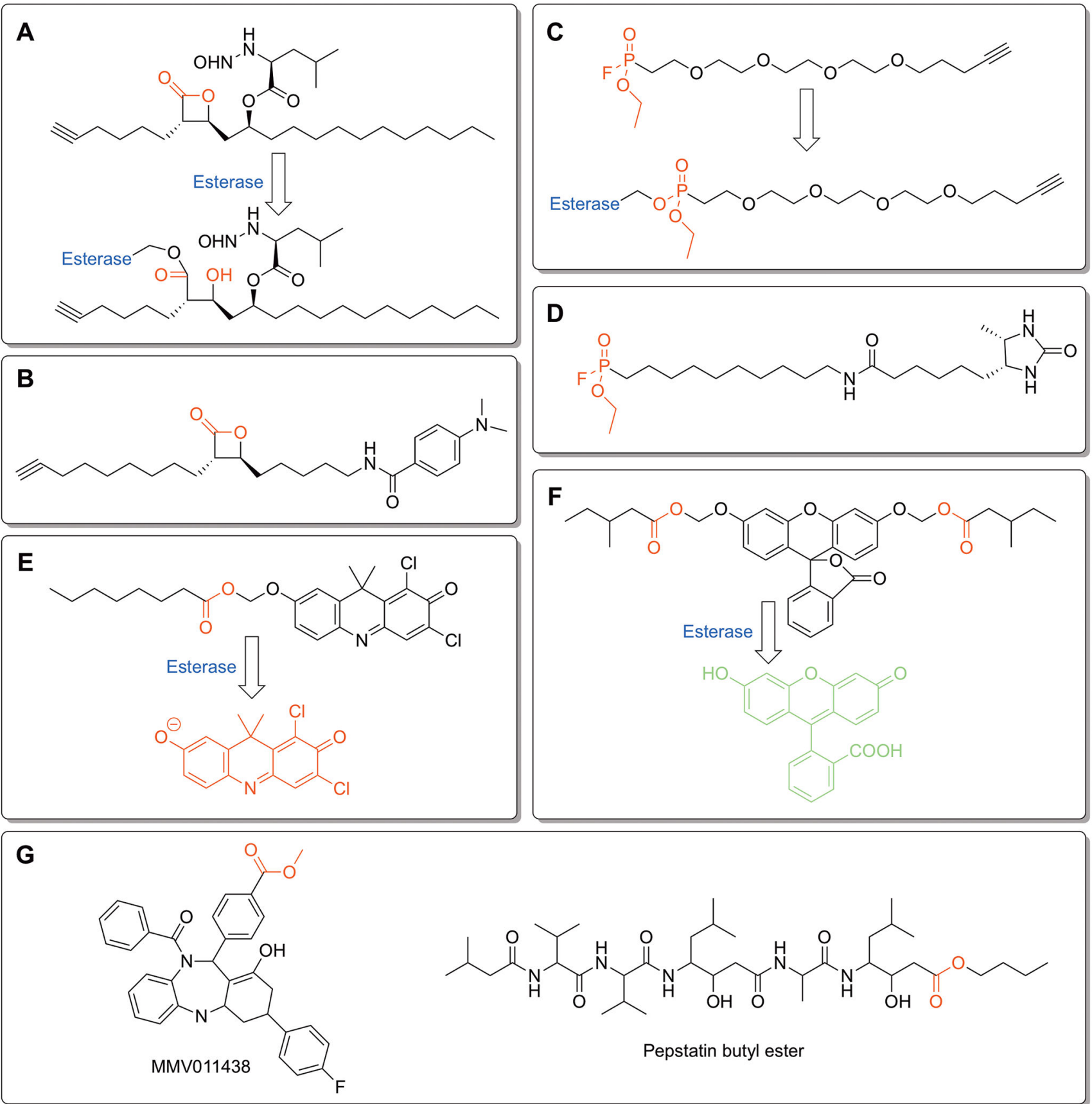

Figure 2:

Profiling bacterial esterases. A - D) Activity based protein profiling (ABPP) ligands used to characterize proteome-wide esterase activity in Mycobacteria and to identify esterase activity present under disease relevant growth conditions.[Lehmann et al. 2018; Ortega et al. 2016; Ravindran et al. 2014; Tallman et al. 2016b] Each ligand contains an electrophilic moiety (labeled in red) for covalent labeling of esterases and an alkyne for isolation and identification of labeled esterases by click chemistry. A) Tetrahydrolipstatin (THL)-alkyne. [Ravindran et al. 2014] B) Modified version of THL-alkyne (EZ120) designed to mimic 
mycolic acids on the $M t b$ mycomembrane.[Lehmann et al. 2018] C) FluorophosphonatePEG-alkyne.[Ortega et al. 2016] D) Desthiobiotin-fluorophosphonate.[Tallman et al. 2016b] $\mathrm{E}$ and F) Complementary fluorogenic ester substrates used to measure dynamic esterase activity under disease-related growth conditions.[Bassett et al. 2018; Tallman and Beatty 2015; Tallman et al. 2016a; Tallman et al. 2016b] Cleavage of ester moieties (labeled red) by a bacterial esterase transitions the fluorophore from a stable non-fluorescent form into a highly fluorescent state. Changing the ester moieties and screening the resulting fluorogenic libraries have identified ester moieties with specificity to pathogenic Mycobacteria species (E)[Tallman et al. 2016a; Tallman et al. 2016b] and to dormant growth conditions (F). [Bassett et al. 2018] E) DDAO (7-hydroxy-9H-1,3-dichloro-9,9-dimethylacridin-2-one)acyloxymethyl ether probe.[Tallman et al. 2016a; Tallman et al. 2016b] The eight-carbon acyloxymethyl ether probe was the most selective for pathogenic Mycobacteria esterases. F) Fluorescein acyloxymethyl ether esterase probe.[Bassett et al. 2018] A variety of hydrophobic and long-chain esters, including a fluorescein bis((4-methyl)valeryloxymethyl ether) derivative, were selectively activated under nutrient starvation growth conditions. G) Two anti-malarial prodrugs selectively activated by PfPARE.[Istvan et al. 2017] The ester prodrug moiety that increases cell permeability and is selectively removed by PfPare within $P$. falciparum is shown in red.

Drug Dev Res. Author manuscript; available in PMC 2020 February 01. 

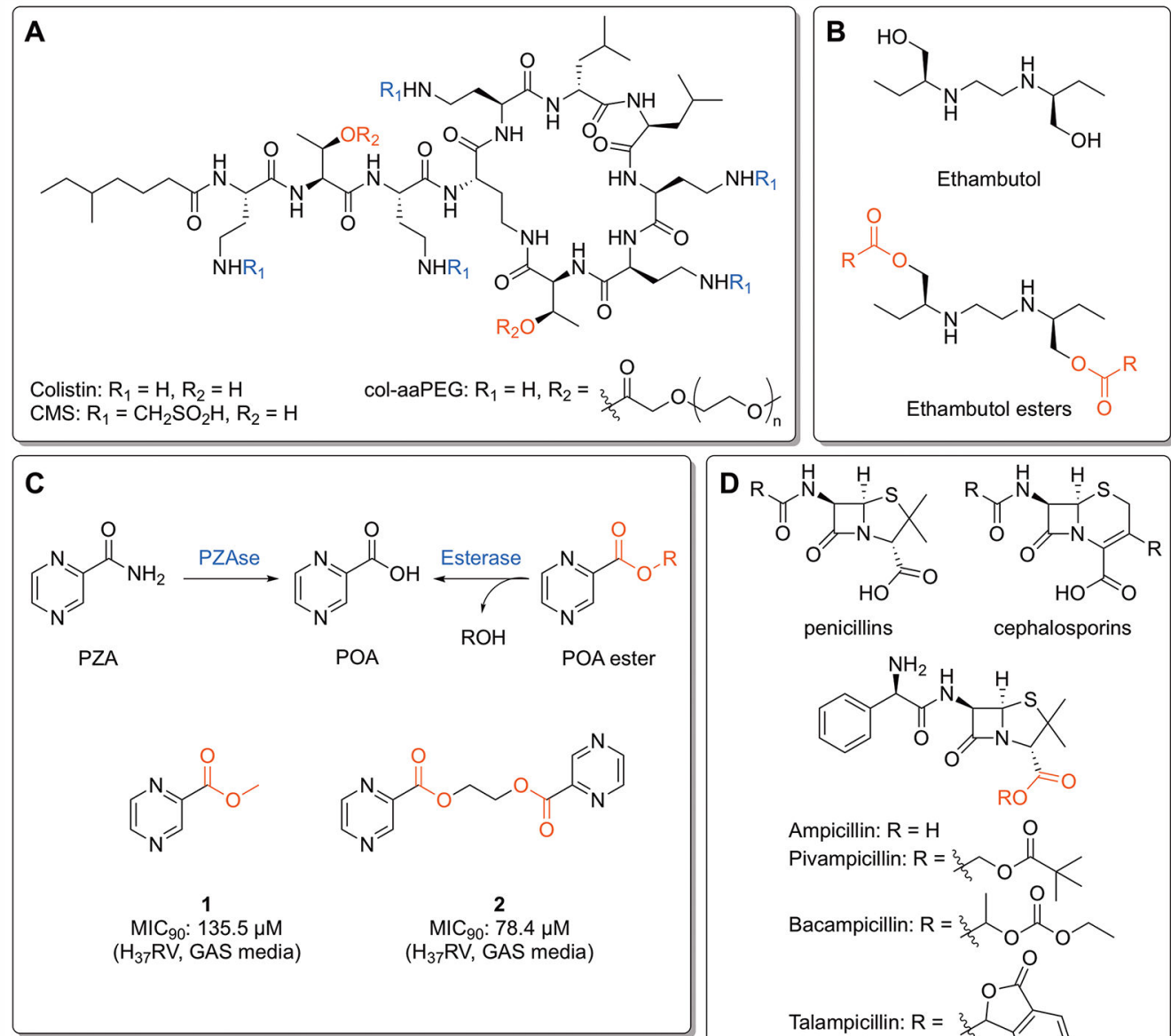

E<smiles>O=C(O)c1cn(C2CC2)c2cc(N3CCNCC3)c(F)cc2c1=O</smiles>

Ciprofloxacin: $\mathrm{R}=\mathrm{H}$

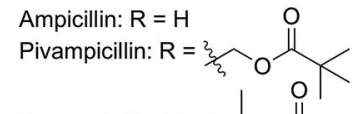
Bacampicillin: $\mathrm{R}=z_{\xi}$ Talampicillin: $\mathrm{R}=$ Lenampicillin: $\mathrm{R}=z_{2}$

$\mathbf{F}$

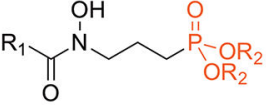

Fosimydomycin: $\mathrm{R}_{1}=\mathrm{H}, \mathrm{R}_{2}=\mathrm{H}$ FR900098: $\mathrm{R}_{1}=\mathrm{CH}_{3}, \mathrm{R}_{2}=\mathrm{H}$ Acetyloxyethyl ester: $\mathrm{R}_{1}=\mathrm{CH}_{3}, \mathrm{R}_{2}=$ POM ester: $\mathrm{R}_{1}=\mathrm{CH}_{3}, \mathrm{R}_{2}=\xi_{3}$

Figure 3:

Classic, clinical, and pre-clinical ester prodrugs. A) Colistin, colistin methanesulfonate (CMS),[Bergen et al. 2006] and the mono-aaPEG polymer (col-aaPEG).[Zhu et al. 2017] The PEG esters are hydrolyzed by plasma esterases at $37^{\circ} \mathrm{C}$ to yield colistin. B) Ethambutol and ethambutol esters. Ester prodrugs are inactive against mycobacteria until hydrolyzed by an esterase. $\mathrm{R}$ groups include alkyl chains, cycloalkyl groups and branched alkyl functionalities.[Larsen et al. 2017] C) The pyrazinamide (PZA) and pyrazinoic acid (POA) ester activation pathways. POA esters demonstrate activity against resistant strains of 
mycobacteria that lack pyranizamidase (PZAse), instead being activated by internal esterases. The "duplicated" prodrug $\mathbf{2}$ shows increased efficacy over $\mathbf{1}$ due to increased intracellular concentrations of POA.[Segretti et al. 2016] D) Core structures of the penicillins and cephalosporins, along with ampicillin and its ester prodrugs. The different ester moieties are designed to improve lipophilicity and oral bioavailability. [Bodin et al. 1975; Clayton et al. 1976; Sakamoto et al. 1984; Sjövall et al. 1978] E) Ciprofloxacin and various ester prodrugs and conjugates. PEGlyated prodrugs are designed to disrupt crystallinity and enhance solubility.[Assali et al. 2016] The ciprofloxacin-anhydride coating is engineered to be cleaved by extracellular esterases,[Komnatnyy et al. 2014] and the nanoantibiotic is designed to be cleaved by internal esterases following disruption of the bacterial cell wall by the carbon nanotube.[Assali et al. 2017] F) Fosimydomycin, FR900098, and two FR900098 phosphonate esters. The acetyloxyethyl ester demonstrates enhanced activity against malaria due to increased oral absorption,[Phillips et al. 2015] while the pivaloyloxymethyl (POM) ester activates FR900098 against Mtb.[Uh et al. 2011]

Drug Dev Res. Author manuscript; available in PMC 2020 February 01. 

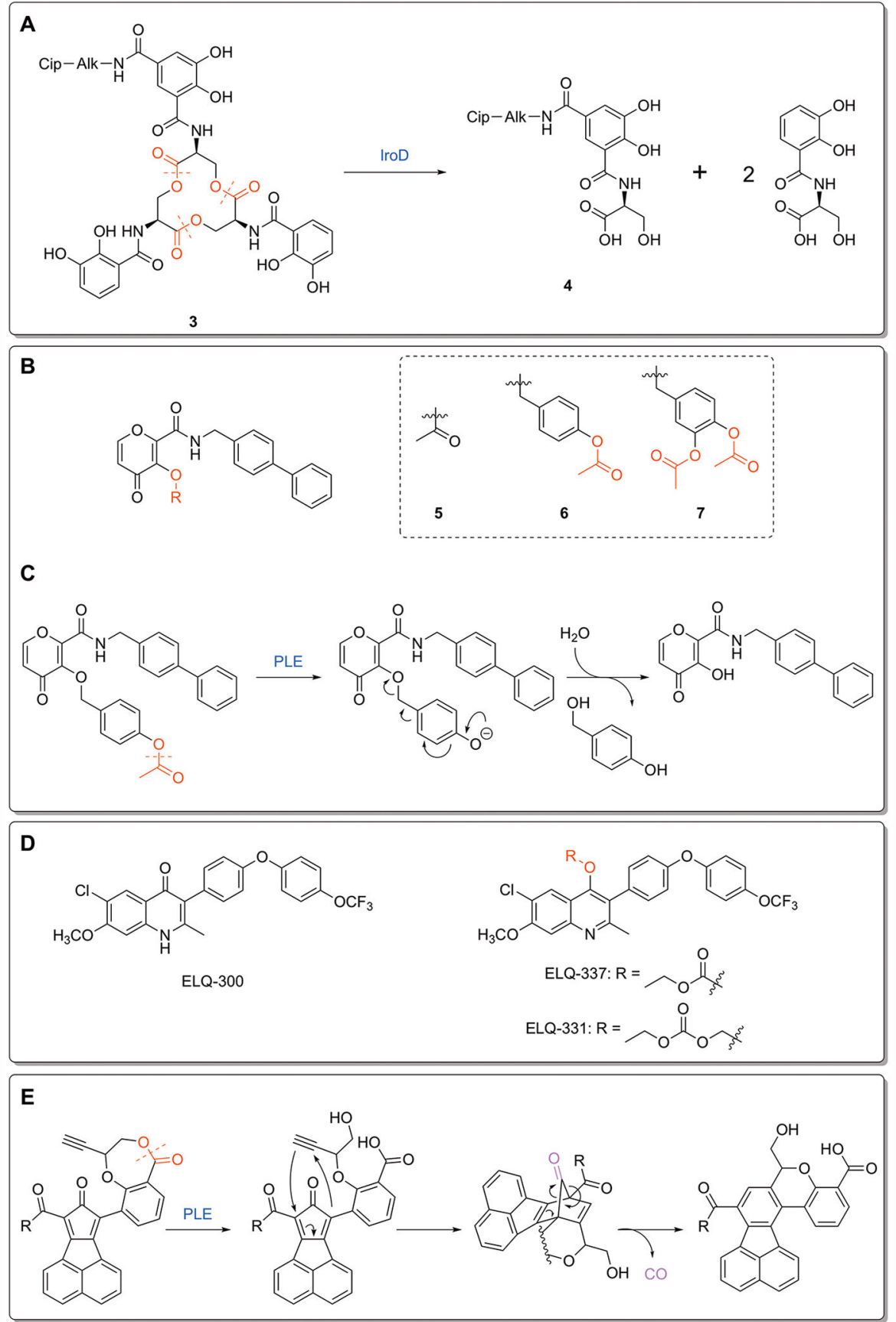

Figure 4:

Novel ester prodrugs and mechanisms. A) Decomposition of the ciprofloxacin-enterobactin conjugate 3. IroD-catalyzed hydrolysis breaks apart the siderophore, leaving behind the monocatecholate product 4.[Neumann et al. 2018] B) Ester prodrugs of the metalloproteinase proinhibitor PY-2: methyl ester 7, benzyl ether linked $\mathbf{8}$, and catechol linked 9. C) Mechanism of ester-responsive trigger for $\mathbf{8}$. Hydrolysis of the protecting methyl ester leads to decomposition of the benzyl ether, yielding the parent inhibitor.[Perez et al. 2013] D) ELQ-300 and its carbonate and alkoxycarbonate esters. The ester 
functionality disrupts the planar compound and decreases crystallinity, which enhances oral absorption.[Frueh et al. 2017] E) Release mechanism for metal-free CO prodrugs. Esterase activation opens the 7-membered lactone ring, freeing the alkyne functionality to undergo Diels-Alder cycloaddition with the cyclopentadienone core. The intermediate rearranges to release $\mathrm{CO}$ and the final cyclization product.[Ji et al. 2017] 